\title{
LncRNA HOTAIR regulates the expression of E- cadherin to affect nasopharyngeal carcinoma progression by recruiting histone methylase EZH2 to mediate H3K27 trimethylation
}

\section{Feng-lian Yang}

center of reproductive and genetic medicine,affiliated hospital of youjiang medical college for nationalities

\section{Yu-xia Wei}

center of reproductive and genetic medicine,affiliated hospital of youjiang medicine college ofr nationalities

\section{Bi-yun Liao}

center of reproductive and genetic medicine,affiliated hospital of youjiang medical college for nationalities

\section{Gui-jiang Wei}

center of reproductive and genetic medicine,affiliated hospital of youjiang medical college for nationalities

\section{Hai-mei Qin}

center of reproductive and genetic medicine,affiliated hospital of youjiang medical college for nationalities

\section{Xiao-xia Pang}

center of reproductive and genetic medicine,affiliated hospital of youjiang medical college for nationalities

Jun-li Wang ( $\square$ baisewangjunli@126.com )

center of reproductive and genetic medicine,affiliated hospital of youjiang medical college ofr nationalities

\section{Research}

Keywords: Nasopharyngeal carcinoma, LncRNA HOTAIR, EZH2, E-cadherin, H3K27 (H3K27me3)

Posted Date: July 20th, 2020

DOI: https://doi.org/10.21203/rs.3.rs-41892/v1 
License: (c) (i) This work is licensed under a Creative Commons Attribution 4.0 International License. Read Full License

Version of Record: A version of this preprint was published at Genomics on July 1st, 2021. See the published version at https://doi.org/10.1016/j.ygeno.2021.03.036. 


\section{Abstract \\ Background/Aim:}

In recent years, there has been increasing evidence for the function of long non-coding RNA (IncRNA) in nasopharyngeal carcinoma (NPC).. We aim to delve into the position of IncRNA HOTAIR, together with $\mathrm{EZH} 2$, E-cadherin and H3K27me3 in NPC and explore the related mechanisms.

\section{Methods}

RT-qPCR and western blot analysis were carried out for detecting IncRNA HOTAIR, EZH2, E-cadherin and H3K27me3 expression in NPC tissues and cells. Moreover, the correlations between IncRNA HOTAIR and EZH2 expression and the clinicopathological characteristics and prognosis of patients with NPC were observed. NPC cell biological functions were examined through gain-of and loss-of function assays. RIP and ChIP assays were applied to detect whether IncRNA HOTAIR in NPC cells could regulate E-cadherin by recruiting EZH2 to mediate trimethylation of H3K27.

\section{Results}

LncRNA HOTAIR, EZH2, and H3K27me3 were richly expressed in NPC tissues and cells, and E-cadherin was lowly expressed. The prognosis of patients with overexpression of IncRNA HOTAIR and EZH2 was worse than that of patients with theirs low expression. Down-regulation of either HOTAIR or EZH2 inhibited cell proliferation, promoted apoptosis, suppressed migration and invasion and inhibited tumor growth. HOTAIR recruited histone methylase EZH2 to mediate trimethylation of H3K27 and regulated Ecadherin expression.

\section{Conclusion}

Our study suggests that IncRNA HOTAIR inhibits the expression of E-cadherin by stimulating the trimethylation of $\mathrm{H} 3 \mathrm{~K} 27$ by histone methylase $\mathrm{EZH} 2$ to promote cell migration, proliferation, and inhibit apoptosis of NPC cells.

\section{Introduction}

Nasopharyngeal carcinoma (NPC) is a general term for a group of malignant epithelial tumors with varying pathogenesis and extensive histopathology [1]. Macroscopically speaking, it is not a prevailing disease over the world but a prevalence in southern China, especially in Guangdong province [2]. Over the past years, evidence has shown that the risk factors for NPC include viral-related factors such as EpsteinBarr virus (EBV) and environmental factors like chemical products, domestic fume intake from incomplete combustion of coal and wood [3,4]. Radiotherapy is the primary treatment of NPC and 
combination chemotherapy can enhance treatment outcomes for locoregionally advanced disease [5]. However, NPC patients carry a high potential for metastasis and immune escape, with a great risk of relapse after primary treatment [6]. Therefore, it is an urgency to prospect a practical therapy for NPC.

Long non-coding RNA HOX antisense intergenic RNA (IncRNA HOTAIR), a crucial cancer-related IncRNA in gene regulation, has convinced its function in tumorigenesis and metastasis in diverse carcinomas [7]. It has been discussed that IncRNA HOTAIR owns the prognostic function for NPC progression and survival [8]. About the enhancer of zeste homolog 2 (EZH2), which is a contributor to cell cycle regulation and tumorigenesis, is enhanced in NPC; and ectopic EZH2 overexpression is able to induce invasion of NPC cells, and E-cadherin is reduced [9]. Concerning to E-cadherin, it is concluded that decreased expression of E-cadherin has been established as a feature of epithelial-mesenchymal transition in epithelial malignancies [10]. The trimethylation of lysine 27 on histone H3 (H3K27me3), a transcriptional inhibitory histone modification involving tumorigenesis is methylated by EZH2 [11]. Additionally, the fact that increased expression of EZH2 leads to histone H3K27 trimethylation promotion and thus represses Ecadherin [12], which consolidates that there is a functional link between EZH2, histone H3K27 trimethylation and E-cadherin. Based on the findings mentioned above, the relationships and interactions among IncRNA HOTAIR, EZH2, H3K27 trimethylation and E-cadherin still remain to be investigated in depth. The objective of the present study is to pave the way for future NPC treatment.

\section{Materials And Methods}

\section{Ethics statement}

The study was approved by the Ethics Committee of Affiliated hospital of Youjiang Medical College for Nationalities and informed written consent was gained from all patients. All animal experiments were in line with the Guide for the Care and Use of Laboratory Animal by International Committees.

\section{Study subjects}

A total of 83 patients with NPC (aged at 21-78 years old with the mean age of 54 years old) were collected from who received radiotherapy in Affiliated hospital of Youjiang Medical College for Nationalities from June 2012 to June 2014, of which there were 47 cases of male and 36 of female with complete clinical materials through pathological examination diagnosis. According to the International Union Against Cancer (UICC) TNM staging standard issued in 2002, there were 7 cases in stage I, 21 cases in stage II, 35 cases in stage III, and 20 cases in stage IV; and 58 cases with cervical lymph node metastasis (LNM) and 25 cases without. In the $\mathrm{N}$ stage, there were 25 cases of N0, 9 cases of N1, 41 cases of N2, and 8 cases of N3. Any anti-cancer treatments including radiotherapy and chemotherapy have never been adopted by all patients with NPC before biopsy. Cancer tissue was collected accompanied by a control group of normal tissue from 32 cases of chronic nasopharyngeal mucosal inflammatory tissue in patients with chronic sinusitis. Follow-up was performed for 60 months by outpatient or telephone after radiotherapy until June 30, 2019. 


\section{Hematoxylin-eosin (HE) staining}

Paraffin-embedded chronic nasopharyngeal mucosal inflammatory tissues and NPC tissues were dewaxed in xylene I and xylene $\otimes$ for 10 min respectively and in xylene $\nabla$ if not be transparent. After the residual xylene was removed, the tissues were treated with absolute ethanol, $95 \%$ alcohol, $80 \%$ alcohol, $70 \%$ alcohol respectively for 3 min, rinsed with running water and distilled water for 2 min respectively and stained in hematoxylin solution for $5 \mathrm{~min}$. Next, the tissues went on differentiation with $1 \%$ hydrochloric acid alcohol solution twice for 10 s per time, rinsed with running water, and treated with $1 \%$ eosin solution and rinsed with running water again. Finally, the tissues were dehydrated in $70 \%$ alcohol,

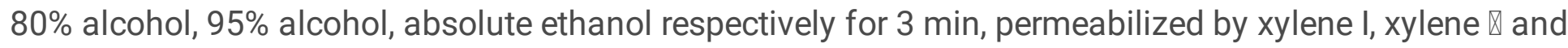
xylene $\otimes$ for 5 min and sealed with neutral resin for observation.

\section{Immunohistochemical staining with the streptavidin- peroxidase (SP) assay}

Immunohistochemical SP method kit (Fuzhou Maxim Biotechnology Co., Ltd., Fuzhou, China) was applied to detect E-cadherin and H3K27me3 expression in tissues. Firstly, the tissues were baked for $1 \mathrm{~h}$ at $60^{\circ} \mathrm{C}$, dewaxed in xylene for $10 \mathrm{~min}$, hydrated with absolute ethanol and gradient alcohol for $3 \mathrm{~min}$, and rinsed the phosphate buffered saline (PBS) 3 times for 3 min each time. Subsequently, tissue antigen retrieval was performed at $1500 \mathrm{~mL}$ citrate antigen retrieval solution $(0.01 \mathrm{M}, \mathrm{pH} 6.0)$ at $121^{\circ} \mathrm{C}$ for $2 \mathrm{~min}$. The tissues were incubated with $50 \mu \mathrm{L}$ of Reagent $A$ (endogenous peroxidase blocker) for $30 \mathrm{~min}$ at room temperature. Next, $50 \mu \mathrm{L}$ of reagent B (normal non-immune animal serum) was dropped and the tissues were incubated to block non-specific antigen. After serum removing, $50 \mu \mathrm{L}$ of primary antibody (PBS instead of primary antibody was added for the negative control (NC)) was added and incubated overnight at $4{ }^{\circ} \mathrm{C}$. After warming the next day and washing with PBS, the tissues were added with $50 \mu \mathrm{L}$ of reagent $C$ (biotin-labeled secondary antibody) and incubated for $30 \mathrm{~min}$ at room temperature. One drop of newly prepared diaminobenzidine (DAB) coloring solution was added and later washed away with tap water to stop the color reaction. And the tissues were immersed $3 \mathrm{~min}$ in hematoxylin dye solution, differentiated in $1 \%$ hydrochloric acid alcohol for $10 \mathrm{~s}$, dehydrated for in gradient alcohol for $5 \mathrm{~min}$ before permeabilization, sealed with the neutral resin and observed under the microscope for analysis.

\section{Cell selection and culture}

NPC cells 6-10B, S18, CNE2, HONE1, and C666-1 were provided by Shanghai Huiying Biotechnology Co., Ltd. (Shanghai, China) and NP69, the normal nasopharyngeal epithelial cell line by Jianglin Biotechnology Co., Ltd. (Shanghai, China). Cells were cultured as required in RPMI 1640 medium (Gibco, Grand island, NY, USA) containing $10 \%$ fetal bovine serum (FBS, Gibco) in a incubator at $37^{\circ} \mathrm{C}$ with $5 \%$ $\mathrm{CO}_{2}$, and medium was changed every 2 days. When cells reached $80 \% \sim 90 \%$ confluence, cell passage was to start. The logarithmic growth phase cells in 2 to 3 stable passages were taken to determine the expression of HOTAIR and EZH2 by reverse transcription quantitative polymerase chain reaction (RTqPCR) and EZH2 protein level by Western blot analysis. Subsequent experiments were performed with 
S18 cells with the greatest differential expression of human nasopharyngeal epithelial cell line NP69 and minimally differentiated 6-10B cells.

\section{Cell grouping and transfection}

S18 and 6-10B cells $\left(1 \times 10^{5}\right.$ cells/well) in logarithmic growth phase were seeded into 24-well cell culture plates and transfected until cells reached 80\% confluence in accordance with lipofectamine 2000 kit instructions (Invitrogen, Carlsbad, California, USA). Each transfection sequence was diluted in $3 \mathrm{~mL}$ serum-free RPMI 1640 medium (both from Shanghai GenePharma Co., Ltd., Shanghai, China, with a final concentration of $50 \mathrm{nM}$ ), mixed and incubated. Next, $600 \mu \mathrm{L}$ lipofectamine 2000 was diluted with $3 \mathrm{~mL}$ serum-free RPMI 1640 medium, mixed and incubated. The above-mentioned two were mixed together and incubated and then added to the cell culture well. After 6 -hours culture at $37^{\circ} \mathrm{C}, 5 \% \mathrm{CO}_{2}$ with saturated humidity, cells were cultured in RPMI 1640 medium containing 10\% FBS for subsequent experiments rather than the medium containing transfection solution.

S18 cells were divided into 7 groups, including Blank-S18 group (cells without any treatment), sh-NC group with S18 cell line transfected with poorly expressed HOTAIR vector NC, sh-HOTAIR group with S18 cell line transfected with poorly expressed HOTAIR vector, sh-Ctr group with S18 cell line transfected with poorly expressed EZH2 vector NC, sh-EZH2 group with $\mathrm{S} 18$ cell line transfected with poorly expressed EZH2 vector, sh-HOTAIR + overexpression (OE)-Ctr group with S18 cell line transfected with poorly expressed HOTAIR vector and then transfected with over-expressed EZH2 vector NC and sh-HOTAIR + OeEZH2 group with S18 cell line transfected with poorly expressed HOTAIR vector and then transfected with over-expressed EZH2 vector.

Seven groups were separated from 6-10B cells, including Blank-6-10B group without any treatment for 610B cell line, Oe-NC group with 6-10B cell line transfected with over-expressed HOTAIR vector NC, OeHOTAIR group with 6-10B cell line transfected with over-expressed HOTAIR vector, Oe-Ctr group with 6-10B cell line transfected with over-expressed EZH2 vector NC, Oe-EZH2 group with 6-10B cell line transfected with over-expressed EZH2 vector, Oe-HOTAIR + sh-Ctr group with 6-10B cell line transfected with overexpressed HOTAIR vector and transfected with poorly expressed EZH2 vector NC, Oe-HOTAIR + sh-EZH2 group with 6-10B cell line transfected with over-expressed HOTAIR vector and transfected with poorly expressed $\mathrm{EZH} 2$ vector.

\section{3-(4,5-Dimethylthiazol-2-yl)-2,5-diphenyltetrazolium bromide (MTT) assay}

S18 and 6-10B cells in logarithmic growth phase were inoculated into a 96-well plate at $200 \mu \mathrm{L}$ cell suspension per well with the cell concentration adjusted to $2 \times 10^{5}$ cells $/ \mathrm{mL}$. With 24-h culture, $200 \mu \mathrm{L}$ RPMI 1640 containing 10\% FBS was replaced after cell adherence, and $20 \mu \mathrm{L}$ of $5 \mathrm{mg} / \mathrm{mL}$ MTT solution was added to each well after 0 h, 24 h, 48 h, and $72 \mathrm{~h}$ respectively. Then cells were incubated for $4 \mathrm{~h}$ at $37^{\circ} \mathrm{C}$, centrifuged and washed with PBS for 3 times with the supernatant discarded. Next, $150 \mu \mathrm{L}$ of dimethyl sulphoxide (DMSO) was added per well and placed on the shaking table for 10 min. The optical 
density (OD) values of the wells were measured at a wavelength of $492 \mathrm{~nm}$ on a M450 microplate reader (Bio-Rad, CA, USA) when the blue crystals were sufficiently dissolved.

\section{Colony formation assay}

S18 and 6-10B cells were detached with $0.25 \%$ trypsin, and stained with trypan blue to count the number of viable cells. Then, RPMI 1640 medium containing 10\% FBS was applied to dilute the cell suspension and cells were inoculated and evenly dispersed into a $6 \mathrm{~cm}$ cell culture dish at 1000 cells $/ 10 \mathrm{~mL}$, which was cultured in an incubator at $37^{\circ} \mathrm{C}$ with $5 \% \mathrm{CO}_{2}$ for $12-15$ days. Next, cells were separated from culture solution, rinsed with PBS twice and fixed with $10 \mathrm{~mL}$ of $4 \%$ paraformaldehyde for $20 \mathrm{~min}$. Finally, departed from paraformaldehyde, the cells were treated with crystal violet staining solution which was washed away 30 min later and dried at room temperature. And the culture dish was photographed under a microscope and the number of cell colonies was counted.

\section{Flow cytometry}

First, the transfected S18 and 6-10B cells in each group were incubated with $100 \mu \mathrm{L}$ of propidium iodine (PI)-Rnase A without light exposure and analyzed by flow cytometry to compare the DNA content in each cell phase. Second, cells were detached, centrifuged, washed twice with PBS, suspended with pre-cooled $75 \%$ ethanol and fixed at $-20^{\circ} \mathrm{C}$ overnight. Third, cells were centrifuged again with the supernatant discarded, washed twice with PBS and resuspended in $450 \mu \mathrm{L}$ of PBS per sample. Last, cells were treated with $100 \mu \mathrm{L}$ of Rnase $\mathrm{A}$ at $37^{\circ} \mathrm{C}$ and stained with $400 \mu \mathrm{L}$ of $\mathrm{PI}$ at $4^{\circ} \mathrm{C}$ without light exposure for $30 \mathrm{~min}$ and cell cycle status was measured and analyzed by BD flow cytometry (BD Biosciences, Mountain View, CA, USA). Cell apoptosis was detected by flow cytometry with the supplement of $5 \mu \mathrm{L}$ of Annexin-V FITC and $10 \mu \mathrm{L}$ of PI.

\section{Hoechst33342 staining}

The S18 and 6-10B cells were inoculated in 24-well plates at $2 \times 10^{4}$ per well after detachment. When the cell reached $70 \%$ confluence, they were cultured for $12 \mathrm{~h}$ with serum-free medium and fixed with $1 \mathrm{~mL}$ of $4 \%$ paraformaldehyde at $20^{\circ} \mathrm{C}$ for $20 \mathrm{~min}$. After that, the cells were stained with $1 \mathrm{~mL}$ of Heochst 33342 dye per well at $37^{\circ} \mathrm{C}$ in an incubator. At last, the cells were recorded and photographed under an inverted fluorescence microscope.

\section{Cell migration assay}

The Transwell chamber with a polycarbonate membrane pore size of $0.8 \mu \mathrm{m}$ was placed in a 24-well culture plate. Suspensions of $\mathrm{S} 18$ and $6-10 \mathrm{~B}$ with a density of $3 \times 10^{5}$ cells $/ \mathrm{mL}$ in serum-free medium were added into the upper chamber at $200 \mu \mathrm{L} /$ well and $0.5 \%$ bovine serum albumin (BSA) was used to maintain the upper osmotic pressure. The medium containing $10 \%$ serum was added into the lower chamber at $600 \mu \mathrm{L} /$ well and incubated in a $5 \% \mathrm{CO}_{2}$ incubator at $37^{\circ} \mathrm{C}$. After $24 \mathrm{~h}$, the upper chamber was fixed in $4 \%$ paraformaldehyde for 20 min, air-dried and stained in $0.1 \%$ crystal violet dye for $30 \mathrm{~min}$, decolorized twice with water, and the residual cells in the upper chamber were scraped off with a cotton swab.When the chamber was air-dried, five fields of view were randomly selected under the microscope 
for photographing, and the cells were counted by ImageJ image processing software for statistical analysis.

\section{Cell invasion assay}

The Matrigel-coated Transwell chamber was put into a 24-well culture plate, suspensions of each group of $\mathrm{S} 18$ and $6-10 \mathrm{~B}$ with a density of $3 \times 10^{5} \mathrm{cells} / \mathrm{mL}$ in serum-free medium were prepared and added into the upper chamber at $200 \mu \mathrm{L} /$ well with the osmotic pressure maintaining. And the medium with $10 \%$ serum was added to the lower chamber that were incubated at $37{ }^{\circ} \mathrm{C}$ in a $5 \% \mathrm{CO}_{2}$ incubator. After 48 hours, the upper chamber was fixed with $4 \%$ paraformaldehyde, air-dried, stained with crystal violet dye, decolorized, photographed, counted, and statistically analyzed.

\section{Tumorigenesis in nude mice}

Seventy clean BALB/c nude mice (Hunan SJA Laboratory Animal Co., Ltd., Hunan, China), weighing 20$25 \mathrm{~g}$, were raised adaptively for $7 \mathrm{~h}$ in line with the rules of animal protection and use with room temperature of $25 \pm 2{ }^{\circ} \mathrm{C}$, relative humidity $65 \% \sim 70 \%, 12$ hours of light and 12 hours of dark cycle, good ventilation, hygienic cages and free drinking water. A total of $0.1 \mathrm{~mL}$ of $\mathrm{S} 18$ and $6-10 \mathrm{~B}$ cells $\left(4 \times 10^{7}\right.$ cells $/ \mathrm{mL}$ ) in the logarithmic phase was subcutaneously injected into the back of the nude mice, and the tumor length and short diameters of nude mice were recorded by vernier calipers on the 3rd, 6th, 9th, 12th, 15 th, 18 th and 21 st day respectively. On the 21 st day, the weight of the anatomical tumor tissue was measured after euthanasia of the nude mice.

\section{Reverse transcription quantitative polymerase chain reaction (RT-qPCR)}

The total RNA in NPC tissue, chronic nasopharyngeal mucosal inflammatory tissue and S18, 6-10B cells were extracted by Trizol (Takara Co., Ltd., Dalian, China). The instructions of the All-in-One First-Stand cDNA Synthesis Kit (GeneCopoeia, Maryland, USA) was applied to perform reverse transcription of RNA into cDNA. Designed primers including HOTAIR, EZH2 and E-cadherin were synthesized by Shanghai Genechem Co., Ltd. (Shanghai, China) (Table 1). The mRNA expression of each gene was detected by a real-time PCR kit (Takara), and detected using a real-time PCR instrument (ABI 7500, ABI, Foster City, CA, USA) with glyceraldehyde phosphate dehydrogenase (GAPDH) as an internal reference. The $2^{-\triangle \Delta C t}$ referred to the calculation of the relative expression of each target gene. Each experiment was repeated 3 times. 
Table 1

Primer sequence

\begin{tabular}{|c|c|}
\hline Gene & Primer sequence $\left(5^{\prime}-3^{\prime}\right)$ \\
\hline \multirow[t]{2}{*}{ HOTAIR } & Forward: 5'- AAATATGGCGGCGTCTA CACGGA - 3' \\
\hline & Reverse: 5'-TCCAGAACCCTCTGACATTTGCCT - 3' \\
\hline \multirow[t]{2}{*}{$\mathrm{EZH} 2$} & Forward: 5'-AATCAGAGTACATGCGACT GAGA-3' \\
\hline & Reverse: 5'- GCTGTATCCTTCGCTGTTTCC-3' \\
\hline \multirow[t]{2}{*}{ E-cadherin } & Forward: 5'-TGCCCAGAAAATGAAAAAGG-3' \\
\hline & Reverse: 5'-GTGTATGTGGCAATGCGTTC-3' \\
\hline \multirow[t]{2}{*}{ GAPDH } & Forward: 5'-ТСССАТСАССАТСТTCCA-3' \\
\hline & Reverse: 5'-CATCACGCCACAGTTTTCC-3' \\
\hline $\begin{array}{l}\text { Note: HOTA } \\
\text { epithelial c€ }\end{array}$ & $\begin{array}{l}\text { A HOX transcript antisense RNA; EZH2, enhancer of zeste homolog2; E-cadherin } \\
\text { on molecule; GAPDH, glyceraldehyde phosphate dehydrogenase. }\end{array}$ \\
\hline
\end{tabular}

\section{Western blot analysis}

Total proteins were extracted from tissues and cells of which the protein concentration was measured by bicinchoninic acid test kit instructions (Boster Biological Technology Co., Ltd., Wuhan, Hubei, China). Briefly, proteins were separated by $10 \%$ polyacrylamide gel (Boster), transferred to polyvinylidene difluoride (PVDF) and blocked with 5\% BSA. The membrane was incubated with the primary antibodies EZH2 (1:500, Abcam, Cambridge, UK), H3K27me3 (1:1000, Millipore, Billerica, MA, USA), E-cadherin (1:1000, BD Biosciences) and GAPDH (1:2000, Jackson Immuno Research, Grove, Pennsylvania, USA) at $4{ }^{\circ} \mathrm{C}$ and the horseradish peroxidase (HRP)-labeled secondary antibody (1:2000, Abcam). Images were obtained using an Odyssey two-color infrared fluorescence scanning imaging system. The grayscale values of the bands were measured using the Quantity One image analysis software. The discrepancy between the target bands and internal reference bands was used to compare the differences between the groups.

\section{RNA-binding protein immunoprecipitation (RIP)}

RIP was guided under the instructions of RIP kit (Millipore). S18 and 6-10B cells were resuspended in complete RIP lysate, and incubated on ice. The magnetic beads were triturated, suspended and washed with RIP wash buffer. The sterile enzyme-free eppendorf tubes were labeled as Anti-EZH2, Anti-H3K27me3 and IgG. The magnetic beads were supplemented with RIP wash buffer $(100 \mu \mathrm{L})$ for resuspension, and added with $5 \mu \mathrm{g}$ of the target antibody to incubate, centrifuged and snipped the supernatant. Then the sample was added with $0.5 \mathrm{~mL}$ of RIP wash buffer and placed on the magnetic separator to discard the 
supernatant. Each tube was added with $900 \mu \mathrm{L}$ of RIP immunoprecipitation buffer and cell RIP lysate was centrifuged at $14,000 \mathrm{rpm}$ for $10 \mathrm{~min}$ at $4{ }^{\circ} \mathrm{C}$, and then resuspended in RIP wash buffer. The supernatant $(100 \mu \mathrm{L})$ was added to the RIP immunoprecipitation buffer containing the magnetic bead-antibody complex to make the final total volume as $1 \mathrm{~mL}$ and labeled as Input that was incubated for $3 \mathrm{~h}$ at $4{ }^{\circ} \mathrm{C}$ overnight. The supernatant was discarded on a magnetic separator after centrifugation with $0.5 \mathrm{~mL}$ of RIP elution buffer each tube, which was repeated 5 times. The magnetic bead-antibody complex was resuspended in $150 \mu \mathrm{L}$ of proteinase $\mathrm{K}$ buffer, incubated at $5{ }^{\circ} \mathrm{C}$ for $30 \mathrm{~min}$; the antibody was detached from the magnetic beads, centrifuged briefly and placed on a magnetic separator. The supernatant was transferred to a new tube for RNA purification and RT-qPCR was used to detect the corresponding expression level.

\section{Chromatin immunoprecipitation (ChIP) assay}

Experiment was guided in accordance with the instructions of ChIP test kit (Millipore). The final concentration of $1 \%$ formaldehyde together with S18 and 6-10B cells was incubated on a plate. Then, glycine terminated the crosslinking and the cells were conjugated at $2000 \mathrm{rpm}$ for $5 \mathrm{~min}$ and sonicated together with SDS Lysis Buffer. The cells were conjugated at $10,000 \mathrm{~g}$ to snip impurities. The ultrasonically disrupted product $(100 \mu \mathrm{L})$ was supplemented with $900 \mu \mathrm{L}$ of ChIP Dilution Buffer, $20 \mu \mathrm{L}$ of $50 \times \mathrm{PIC}$ and $60 \mu \mathrm{L}$ of ProteinA Agarose/SalmonSpermDNA, and then were mixed at $4{ }^{\circ} \mathrm{C}$ for $1 \mathrm{~h}$, precipitated for $10 \mathrm{~min}$ and centrifuged at $700 \mathrm{rpm}$ for $1 \mathrm{~min}$, of which $20 \mu \mathrm{L}$ was set as the input. One tube with $1 \mu \mathrm{L}$ of EZH2, H3K27me3 and IgG antibody and the other tube without any antibodies were incubated overnight at $4{ }^{\circ} \mathrm{C}$, rinsed, eluted and de-crosslinked, and DNA samples were recovered for RTqPCR detection.

\section{Statistical analysis}

All data analyses were conducted using SPSS21.0 (IBM Co., Armonk, NY, USA). Data were expressed as mean \pm standard deviation. Comparisons between two groups were conducted by $t$-test, while comparisons among multiple groups were assessed by one-way analysis of variance (ANOVA) followed by Tukey's multiple comparisons test. The connection between the expression of HOTAIR and the clinicopathological features of NPC patients was determined by chi-square test. Survival and prognosis of NPC patients was analyzed by Kaplan-Meier. $p<0.05$ was indicative of statistically significant difference.

\section{Results}

LncRNA HOTAIR, EZH2 and H3K27me3 are highly expressed and E-cadherin is poorly expressed in NPC patients

The expression of IncRNA HOTAIR, EZH2 and E-cadherin in NPC tissues and chronic nasopharyngeal mucosal inflammatory tissues were detected by RT-qPCR. HOTAIR and EZH2 expression in the cancer tissues increased in contrast to the normal tissues (both $P<0.05$ ), while E-cadherin expression decreased $(P<0.05)$ (Fig. 1A-C). 
Western blot analysis was conducted to detect EZH2, H3K27me3 and E-cadherin expression in NPC tissues and chronic nasopharyngeal mucosal inflammatory tissues to reveal that of EZH2 and H3K27me3 expression in the cancer tissues increased in contrast to the normal tissues (both $P<0.05$ ) but E-cadherin protein expression decreased $(P<0.05)$ (Fig. 1D).

Immunohistochemical SP method was conducted to observe the expression of E-cadherin and H3K27me3 in NPC tissues and chronic nasopharyngeal mucosal inflammatory tissues. It was found that positive expression of $\mathrm{H} 3 \mathrm{~K} 27 \mathrm{me} 3$ was located at nucleus with light yellow to brown, and the number of the positive cells in the cancer tissues was much more than the normal tissues $(P<0.05)$. The positive expression of E-cadherin was appeared in the cell membrane with brown linear continuous expression. The number of the positive cells in the cancer tissues was less than that in the normal tissues $(P<0.05)$ (Fig. 1E,F).

The NPC tissue and chronic nasopharyngeal mucosal inflammatory tissue were sectioned and treated with HE staining. Microscopically, it was found that in the normal tissues, cells were manifested with neat arrangement, intact structure, uniform staining, and infiltration of secondary lymphoid follicles and their follicular dendritic cells. However, cells in the cancer tissues were demonstrated with damaged structure, evident vacuoles, a small amount of follicular dendritic cells resulting in inflammatory infiltration (Fig. 1G).

\section{Relationship of IncRNA HOTAIR and EZH2 with the clinicopathological features and prognosis of patients with NPC}

Low expression group and high expression group were structured dependent on the mean value of the relative expression of IncRNA HOTAIR. The effect of HOTAIR expression on survival and prognosis of NPC patients was analyzed by Kaplan-Meier and the results explained the difference in survival time between the two groups was statistically significant $(P<0.05)$, and the poorer prognosis appeared among patients with high expression of HOTAIR rather than patients with with low expression (Fig. $1 \mathrm{H}, \mathrm{I})$.

With the same grouping way, the link connecting the effect of HOTAIR and EZH2 mRNA expression with the clinicopathological features of NPC patients was analyzed. The results showed that NPC patients in stage III-IV and stage N2 +3 and with LNM occupied the increased proportion of high expression of HOTAIR and EZH2 mRNA (all $P<0.05$ ), that was, TNM stage, $N$ stage, and LNM were associated with HOTAIR and EZH2 mRNA expression (all $P<0.05$ ), while age and gender were irrelevant to the expression of HOTAIR and EZH2 mRNA (all $P>0.05$ ) (Table 2). 
Table 2

Relationship between relative expression of IncRNA HOTAIR and EZH2 mRNA and clinicopathological features of patients with nasopharyngeal carcinoma

\begin{tabular}{|c|c|c|c|c|c|c|c|}
\hline \multirow{2}{*}{$\begin{array}{l}\text { Clinicopathological } \\
\text { data }\end{array}$} & \multirow[t]{2}{*}{$\mathrm{n}$} & \multicolumn{2}{|c|}{ HOTAIR expression } & \multirow[t]{2}{*}{$P$} & \multicolumn{2}{|c|}{ EZH2 expression } & \multirow[t]{2}{*}{$P$} \\
\hline & & $\begin{array}{l}\text { Low } \\
\text { expression } \\
\text { group }(\mathrm{n}= \\
37)\end{array}$ & $\begin{array}{l}\text { High } \\
\text { expression } \\
\text { group }(\mathrm{n}= \\
46)\end{array}$ & & $\begin{array}{l}\text { Low } \\
\text { expression } \\
\text { group }(n= \\
39)\end{array}$ & $\begin{array}{l}\text { High } \\
\text { expression } \\
\text { group }(n= \\
44)\end{array}$ & \\
\hline \multicolumn{8}{|l|}{ Age (years) } \\
\hline$\geq 54$ & 53 & 23 & 30 & 0.773 & 21 & 32 & 0.074 \\
\hline$<54$ & 30 & 14 & 16 & & 18 & 12 & \\
\hline \multicolumn{8}{|l|}{ Gender } \\
\hline Male & 47 & 20 & 27 & 0.672 & 18 & 29 & 0.070 \\
\hline Female & 36 & 17 & 19 & & 21 & 15 & \\
\hline \multicolumn{8}{|l|}{ TNM stage } \\
\hline$I-I I$ & 28 & 17 & 11 & 0.035 & 21 & 7 & 0.000 \\
\hline III-IV & 55 & 20 & 35 & & 18 & 37 & \\
\hline \multicolumn{8}{|l|}{ N stage } \\
\hline NO & 25 & 17 & 8 & 0.002 & 19 & 6 & 0.002 \\
\hline N1 & 9 & 3 & 6 & & 4 & 5 & \\
\hline $\mathrm{N} 2+3$ & 49 & 17 & 32 & & 16 & 33 & \\
\hline \multicolumn{8}{|l|}{$\begin{array}{l}\text { Lymph node } \\
\text { metastasis }\end{array}$} \\
\hline Yes & 58 & 21 & 37 & 0.020 & 20 & 38 & 0.001 \\
\hline No & 25 & 16 & 9 & & 19 & 6 & \\
\hline
\end{tabular}

\section{LncRNA HOTAIR, EZH2 and H3K27me3 are highly expressed and E-cadherin is poorly expressed in NPC cells}

The expression of IncRNA HOTAIR, EZH2 and E-cadherin in human normal rhinitis epithelial cells NP69 and human NPC cells 6-10B, S18, CNE2, HONE1 and C666-1 were detected by RT-qPCR while EZH2 and $\mathrm{H} 3 \mathrm{~K} 27 \mathrm{me} 3$ and E-cadherin protein expression by Western blot analysis. The experiments results indicated that in contrast to NP69 cells, the expression of HOTAIR, EZH2 and H3K27me3 increased in 6-10B, S18, 
CNE2, HONE1 and C666-1 cells (all $P<0.05)$ and the expression of E-cadherin decreased $(P<0.05)$. The highest levels of HOTAIR, EZH2 and H3K27me3 and the lowest levels of E-cadherin were in S18 cells which had the greatest difference with NP69 cells. The opposite story was in 6-10B cells which had the smallest difference with NP69 cells (Fig. 2A,B). Therefore, S18 and 6-10B cells were selected for subsequent experiments.

The expression of IncRNA HOTAIR, EZH2 and E-cadherin in S18 cells was detected by RT-qPCR and the protein expression of EZH2, H3K27me3 and E-cadherin by Western blot analysis. In relative to sh-NC group, the expression of HOTAIR, EZH2 and H3K27me3 decreased (all $P<0.05$ ), and the expression of Ecadherin increased $(P<0.05)$. Versus the sh-Ctr group, the change of HOTAIR expression in the sh-EZH2 group was not significant $(P>0.05)$, and EZH2 and H3K27me3 protein expression decreased (both $P<$ 0.05), together with increased E-cadherin expression $(P<0.05)$. In contrast to the sh-HOTAIR + Oe-Ctr group, HOTAIR expression changes were not obvious $(P>0.05)$ in the sh-HOTAIR + Oe-EZH2 group, EZH2 and H3K27me3 expression increased (both $P<0.05)$, and E-cadherin expression decreased $(P<0.05)$ (Fig. 2C,D).

The expression of IncRNA HOTAIR, EZH2 and E-cadherin in 6-10B cells was detected by RT-qPCR whereas the protein expression of EZH2, H3K27me3 and E-cadherin by Western blot analysis. By comparison to the Oe-NC group, the expression of HOTAIR, EZH2 and H3K27me3 increased (all $P<0.05$ ), and the expression of E-cadherin decreased $(P<0.05)$ in the Oe-HOTAIR group. Versus the Oe-Ctr group, HOTAIR expression changes in the Oe-EZH2 group was not significant $(P>0.05)$, the expression of EZH2 and H3K27me3 increased (both $P<0.05)$, and the expression of E-cadherin decreased $(P<0.05)$. Compared with the Oe-HOTAIR + sh-Ctr group, HOTAIR expression changes in the Oe-HOTAIR + sh-EZH2 group was insignificant $(P>0.05), \mathrm{EZH} 2$ and $\mathrm{H} 3 \mathrm{~K} 27 \mathrm{me} 3$ expression decreased (both $P<0.05)$, and E-cadherin expression increased $(P<0.05)$ (Fig. 2E,F).

\section{Down-regulation of HOTAIR or down-regulation of EZH2 suppresses cell viability, colony formation ability and cell cycle progression in NPC cells}

In the S18 cell line, the viability, colony formation ability, as well as cell cycle distribution in each group was detected by MTT assay, colony formation assay and flow cytometry, respectively. It was found that the suppressed cell viability at 24th $h$, 48th $h$ and 72th $h$, inhibited colony formation ability, more cells arrested at G0/G1 phrase and fewer cells at $\mathrm{S}$ and G2/M phases were found in the sh-HOTAIR group and the sh-EZH2 group compared to sh-NC group and the sh-Ctr group (all $P<0.05$ ). Compared with the shHOTAIR + Oe-Ctr group, in the sh-HOTAIR + Oe-EZH2 group, there showed promoted cell viability at 24th $\mathrm{h}$, 48th $\mathrm{h}$ and 72th $\mathrm{h}$, induced colony formation ability, fewer cells arrested at G0/G1 phrase and more cells at $S$ and $G 2 / M$ phases (all $P<0.05$ ) (Fig. 3A, C, D, G and H).

In the 6-10B cell line, the viability, colony formation ability, as well as cell cycle distribution in each group was detected by MTT assay, colony formation assay and flow cytometry, respectively. It was found that the promoted cell viability at 24th $h$, 48th $h$ and 72th $h$, induced colony formation ability, fewer cells arrested at G0/G1 phrase and more cells at $\mathrm{S}$ and G2/M phases were found in the Oe-HOTAIR group and 
the Oe-EZH2 group compared to Oe-NC group and the Oe-Ctr group (all $P<0.05$ ). Compared with the OeHOTAIR + sh-Ctr group, in the Oe-HOTAIR + sh-EZH2 group, there showed suppressed cell viability at 24th $h$, 48th $h$ and 72th $h$, inhibited colony formation ability, more cells arrested at G0/G1 phrase and fewer cells at $S$ and $\mathrm{G} 2 / \mathrm{M}$ phases (all $P<0.05$ ) (Fig. 3B, E, F, I and J).

\section{Down-regulation of HOTAIR or down-regulation of EZH2 promotes apoptosis in NPC cells}

Flow cytometry and Hoechst33342 staining were conducted to determine the apoptosis rate of S18 and $6-10 \mathrm{~B}$ cells in each group. The apoptosis rate of cells in the sh-HOTAIR group and sh-EZH2 group was escalated by comparison to sh-NC group and sh-Ctr group respectively (both $P<0.05$ ). Relative to the shHOTAIR + Oe-Ctr group, the apoptosis rate of cells in the sh-HOTAIR + Oe-EZH2 group was decreased $(P<$ 0.05) (Fig. 4A,B and E,F). The apoptosis rate of cells in the Oe-HOTAIR group and the Oe-EZH2 group was decreased compared respectively with the Oe-NC group and the Oe-Ctr group $(P<0.05)$. Versus the OeHOTAIR + sh-Ctr group, the apoptosis rate of cells in the Oe-HOTAIR + sh-EZH2 group was increased $(P<$ 0.05)(Fig. 4C,D and G,H).

\section{Down-regulation of HOTAIR or down-regulation of EZH2 inhibits cell migration and invasion of NPC cells}

Transwell assay was applied to determine the migration and invasion abilities of S18 and 6-10B cells in each group. The cell migration and invasion abilities in the sh-HOTAIR group and the sh-EZH2 group were decreased compared with the sh-NC group and the sh-Ctr group group (all $P<0.05$ ). Relative to the shHOTAIR + Oe-Ctr group, the migration and invasion abilities in the sh-HOTAIR + Oe-EZH2 group were increased (both $P<0.05$ ) (Fig. 5A,B and E,F). The migration and invasion abilities in the Oe-HOTAIR group and the Oe-EZH2 group were increased in contrast to the Oe-NC group and the Oe-Ctr group individually (all $P<0.05$ ). Versus the Oe-HOTAIR + sh-Ctr group, the migration and invasion abilities in the Oe-HOTAIR + sh-EZH2 group were decreased (both $P<0.05)$ (Fig. 5C,D and G,H).

Down-regulation of HOTAIR or down-regulation of EZH2 inhibits tumor growth and tumor volume in nude mice with NPC

The length and width of subcutaneous tumors in nude mice were measured after tumor tumorigenesis so that the tumor volume was calculated to draw the tumor growth curve. It was obvious that after 6 days of S18 cell tumorigenesis, the tumors in each group of nude mice grew to varying degrees with time. After 9 days, the tumor volume in the sh-HOTAIR group and the sh-EZH2 group were suppressed in contrast to the sh-NC group and the sh-Ctr group respectively (both $P<0.05$ ). Versus the sh-HOTAIR + Oe-Ctr group, the tumor volume in the sh-HOTAIR + Oe-EZH2 group was reduced $(P<0.05)$ (Fig. 6A). After 6 days of 6 $10 \mathrm{~B}$ cell tumorigenesis, the tumor volume in the Oe-HOTAIR group and the Oe-EZH2 group were increased compared with the Oe-NC group and the Oe-Ctr group (both $P<0.05$ ). Relative to the Oe-HOTAIR + sh-Ctr group, the tumor volume in the Oe-HOTAIR + sh-EZH2 group was decreased $(P<0.05)$ (Fig. 6B). 
On the 21st day after S18 and 6-10B cell tumorigenesis when the subcutaneous tumors being more obvious, the nude mice were euthanized to obtain the subcutaneous tumors (Fig. $6 \mathrm{C}$ and E). The tumor weight in the sh-HOTAIR group and the sh-EZH2 group were decreased compared with the sh-NC group and the sh-Ctr group (both $P<0.05$ ); compared to the sh-HOTAIR + Oe-Ctr group, the tumor weight in the sh-HOTAIR + Oe-EZH2 group was elevated $(P<0.05)($ Fig. 6D). The tumor weight in the Oe-HOTAIR group and the Oe-EZH2 group were enhanced in contrast to the Oe-NC group (both $P<0.05$ ). In comparison to the Oe-HOTAIR + sh-Ctr group, the tumor weight in the Oe-HOTAIR + sh-EZH2 group was decreased $(P<$ 0.05) (Fig. 6F).

\section{HOTAIR recruits histone methylase EZH2 to mediate trimethylation of $\mathrm{H} 3 \mathrm{~K} 27$ and to regulate E-cadherin expression}

RIP was performed to obtain intracellular RNA from S18 and 6-10B cells. After co-precipitation of proteins with $\mathrm{S} 18$ and $6-10 \mathrm{~B}$ intracellular RNA by EZH2 antibody, the enrichment degree of EZH2 and HOTAIR was detected by RT-qPCR to find that HOTAIR and EZH2 were highly enriched (Fig. 7A,B). To further demonstrate that $\mathrm{EZH} 2$ can mediate $\mathrm{H} 3 \mathrm{~K} 27$ trimethylation binding to the promoter region of E-cadherin and exert its biological effects, ChIP was employed to confirm that EZH2 bound to the E-cadherin promoter region (Fig. $7 C, D$ ). Once knocking down HOTAIR, the binding degree of EZH2 to the E-cadherin promoter region was reduced (Fig. 7E,F).

\section{Discussion}

NPC is an infrequent tumor arising from the nasopharynx epithelium and a nearly unrecognizable disease in the early stage with manifold risk factors [8]. There are comparative studies exposing the regulatory patterns of IncRNA HOTAIR, EZH2, H3K27me3 and E-cadherin in NPC whereas the interactions among them still deserve to be delved. Thus, the purpose of this study is to make an insight into the complex mechanism of these four factors in the progression of NPC, so as to consolidate a theoretical reference for medical care of NPC. Overall, this study clarified that IncRNA HOTAIR recruited histone methylase $\mathrm{EZH} 2$ to mediate the trimethylation of $\mathrm{H} 3 \mathrm{~K} 27$, thus down-regulating the expression of E-cadherin to induce migration and invasion of NPC cells and inhibit apoptosis.

One of the most prominent findings manifested that IncRNA HOTAIR, EZH2 and H3K27me3 were highly expressed and E-cadherin was poorly expressed in NPC tissue and cells. There are also researches in conformity to with our study that the expression of IncRNA HOTAIR [8], EZH2 and H3K27me3 was increased [11, 13], while E-cadherin was decreased in NPC [14]. In the light of our findings, patients with high expression of IncRNA HOTAIR and EZH2 have a worse prognosis than patients with low expression. It was mentioned in a previous study that NPC patients with higher levels of IncRNA HOTAIR had a poor overall survival prognosis [8]. Additionally, our study also found that TNM stage, $\mathrm{N}$ stage, and LNM in patients with NPC were associated with HOTAIR and EZH2 mRNA expression. Evidence has indicated that the association between EZH2 dysfunction and poor prognosis did exist in esophageal squamous 
carcinoma [9]. As demonstrated in a former study, similar results were obtained that higher HOTAIR expression has a higher potential of LNM incidence in cancers and also high level of EZH2 was responsible for LNM in patients with cervical cancer $[15,16]$. Furthermore, the positive relationship between HOTAIR/EZH2 and TNM stage and N classification was convinced in the previous studies [17, 18].

IncRNA HOTAIR knockdown or EZH2 knockdown inhibited NPC cell proliferation, migration and invision and induced apoptosis which was another vital result concluded from our study. Previous study has presented that IncRNA HOTAIR knockdown suppresses cell proliferation and invasion, alters cell cycle progression and motivates apoptosis of non-small cell lung cancer [19]. In addition, the mechanism of HOTAIR in NPC has previously conducted and the result indicated that knockdown of HOTAIR suppresses cell proliferation adn invasion [7]. Besides, EZH2 overexpression has been verified in NPC, reinforcing cell proliferation and neoplastic transformation and contributing to tumor aggressiveness $[13,20]$. Interestingly, that IncRNA HOTAIR and E-cadherin were negatively related in oral squamous cell carcinoma (OSCC) has been clarified and such a result was much more like the result of our study outcome indicating down-regulation of IncRNA HOTAIR stimulates E-cadherin expression in NPC. To be more specific, IncRNA HOTAIR knockdown decreased the enrichment of EZH2 and H3K27 and increased the expression level of E-cadherin in OSCC cells [21]. Considering that, we make the hypothesis reasonably that IncRNA HOTAIR recruits histone methylase EZH2 to mediate trimethylation of H3K27 and to regulate E-cadherin expression in NPC, which consequently is in accordance with our result. Additionally, the present study poses the situation that down-regulation of EZH2 can reverse the effect of up-regulation of IncRNA HOTAIR and up-regulation of EZH2 can also reverse the effect of downregulation of IncRNA HOTAIR on proliferation and apoptosis in NPC. This may pave a new way and widen our horizon to the potent target aiming at NPC.

\section{Conclusion}

In a word, our findings reveal that IncRNA HOTAIR, EZH2 and H3K27me3 are upregulated and E-cadherin is downregulated in NPC tissue and cells. Moreover, HOTAIR could recruit histone methylase EZH2 to mediate trimethylation of $\mathrm{H} 3 \mathrm{~K} 27$ and to regulate E-cadherin expression, thereby promoting the progression of NPC. Hence, the therapeutic strategies for NPC could be guided towards LncRNA HOTAIR, $\mathrm{EZH} 2$ and $\mathrm{H} 3 \mathrm{~K} 27 \mathrm{me} 3$ and E-cadherin. The further exploration of the mechanism should be made in detail and conducted with a large cohort, so as to support a promising application in treatment for patients with NPC.

\section{Declarations}

\section{Conflict of interest}

The authors declare that they have no conflicts of interest. 


\section{Ethical statement}

This study was approved and supervised by the animal ethics committee of Affiliated hospital of Youjiang Medical College for Nationalities. The treatment of animals in all experiments conforms to the ethical standards of experimental animals.

\section{Consent for publication}

Not applicable

\section{Availability of data and material}

Not applicable

\section{Funding}

This study was supported by Foundation of the Education Department of Guangxi Province, China (No. KY2015ZD094); this study was supported by the Foundation of the Nature Science Fund, Guangxi Province, China (No. 2012GXNSFBA053121) ;this study was supported by "139"medical high-level talent training plan and thousands of young and middle-aged backbone teachers cultivation plan of Guangxi Province, China; this study was supported by the 2018-2020 Professional and experimental practice teaching base construction projects of Guangxi Province, China.

\section{Authors' contributions}

Jun-li Wang finished study design, Feng-lian Yang, Yu-xia Wei, Bi-yun Liao finished experimental studies, Feng-lian Yang, Gui-jiang Wei, Hai-mei Qin, Xiao-xia Pang finished data analysis, Feng-lian Yang finished manuscript editing. All authors read and approved the final manuscript

\section{Acknowledgement}

We would like to acknowledge the reviewers for their helpful comments on this paper.

\section{References}

1. Petersson, F., Nasopharyngeal carcinoma: a review. Semin Diagn Pathol, 2015. 32(1): p. 54-73.

2. Jia, W.H., et al., Traditional Cantonese diet and nasopharyngeal carcinoma risk: a large-scale casecontrol study in Guangdong, China. BMC Cancer, 2010. 10: p. 446.

3. Jia, W.H. and H.D. Qin, Non-viral environmental risk factors for nasopharyngeal carcinoma: a systematic review. Semin Cancer Biol, 2012. 22(2): p. 117 - 26. 
4. Aussem, A., S.R. de Morais, and M. Corbex, Analysis of nasopharyngeal carcinoma risk factors with Bayesian networks. Artif Intell Med, 2012. 54(1): p. 53-62.

5. Sze, H., et al., Chemotherapy for Nasopharyngeal Carcinoma - Current Recommendation and Controversies. Hematol Oncol Clin North Am, 2015. 29(6): p. 1107-22.

6. Tang, Y., et al., Co-expression of AFAP1-AS1 and PD-1 predicts poor prognosis in nasopharyngeal carcinoma. Oncotarget, 2017. 8(24): p. 39001-39011.

7. Ma, D.D., L.L. Yuan, and L.Q. Lin, LncRNA HOTAIR contributes to the tumorigenesis of nasopharyngeal carcinoma via up-regulating FASN. Eur Rev Med Pharmacol Sci, 2017. 21(22): p. 5143-5152.

8. Nie, Y., et al., Long non-coding RNA HOTAIR is an independent prognostic marker for nasopharyngeal carcinoma progression and survival. Cancer Sci, 2013. 104(4): p. 458 - 64.

9. Tong, Z.T., et al., EZH2 supports nasopharyngeal carcinoma cell aggressiveness by forming a corepressor complex with HDAC1/HDAC2 and Snail to inhibit E-cadherin. Oncogene, 2012. 31(5): p. 583 - 94.

10. Favaretto, R.L., et al., Prognostic role of decreased E-cadherin expression in patients with upper tract urothelial carcinoma: a multi-institutional study. World J Urol, 2017. 35(1): p. 113-120.

11. Cai, M.Y., et al., H3K27me3 protein is a promising predictive biomarker of patients' survival and chemoradioresistance in human nasopharyngeal carcinoma. Mol Med, 2011. 17(11-12): p. 1137-45.

12. Zhou, Z., et al., Loss of TET1 facilitates DLD1 colon cancer cell migration via H3K27me3-mediated down-regulation of E-cadherin. J Cell Physiol, 2018. 233(2): p. 1359-1369.

13. Lu, J., et al., MiR-26a inhibits cell growth and tumorigenesis of nasopharyngeal carcinoma through repression of EZH2. Cancer Res, 2011. 71(1): p. 225 - 33.

14. Hsu, C.Y., et al., The Epstein-Barr virus-encoded microRNA MiR-BART9 promotes tumor metastasis by targeting E-cadherin in nasopharyngeal carcinoma. PLoS Pathog, 2014. 10(2): p. e1003974.

15. Cai, B., et al., Long noncoding RNA HOTAIR can serve as a common molecular marker for lymph node metastasis: a meta-analysis. Tumour Biol, 2014. 35(9): p. 8445-50.

16. Azizmohammadi, S., et al., High-Level Expression of RIPK4 and EZH2 Contributes to Lymph Node Metastasis and Predicts Favorable Prognosis in Patients With Cervical Cancer. Oncol Res, 2017. 25(4): p. 495-501.

17. Emadi-Andani, E., et al., Association of HOTAIR expression in gastric carcinoma with invasion and distant metastasis. Adv Biomed Res, 2014. 3: p. 135.

18. Guo, L., et al., Role of EZH2 protein expression in gastric carcinogenesis among Asians: a metaanalysis. Tumour Biol, 2014. 35(7): p. 6649-56.

19. Liu, X.H., et al., The long non-coding RNA HOTAIR indicates a poor prognosis and promotes metastasis in non-small cell lung cancer. BMC Cancer, 2013. 13: p. 464.

20. Hwang, C.F., et al., Enhancer of zeste homolog 2 overexpression in nasopharyngeal carcinoma: an independent poor prognosticator that enhances cell growth. Int J Radiat Oncol Biol Phys, 2012. 
82(2): p. 597-604.

21. Wu, Y., et al., Long non-coding RNA HOTAIR promotes tumor cell invasion and metastasis by recruiting EZH2 and repressing E-cadherin in oral squamous cell carcinoma. Int J Oncol, 2015. 46(6):

p. 2586-94.

Figures

A
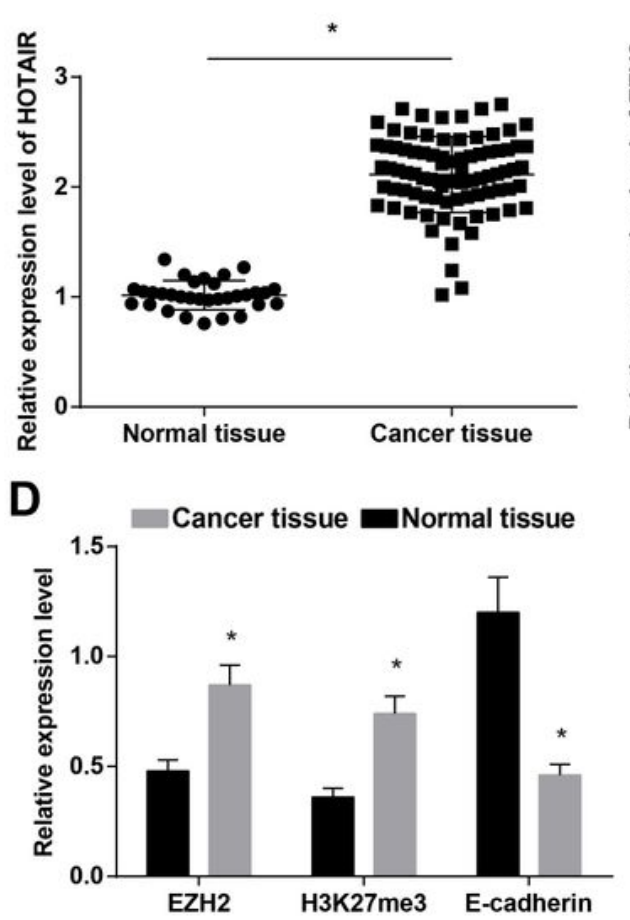

$\mathbf{F}$

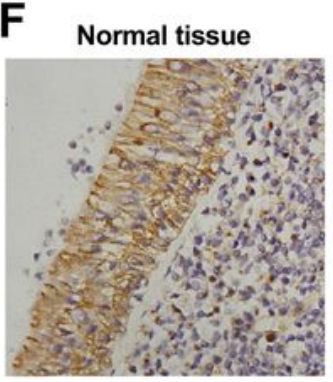

H

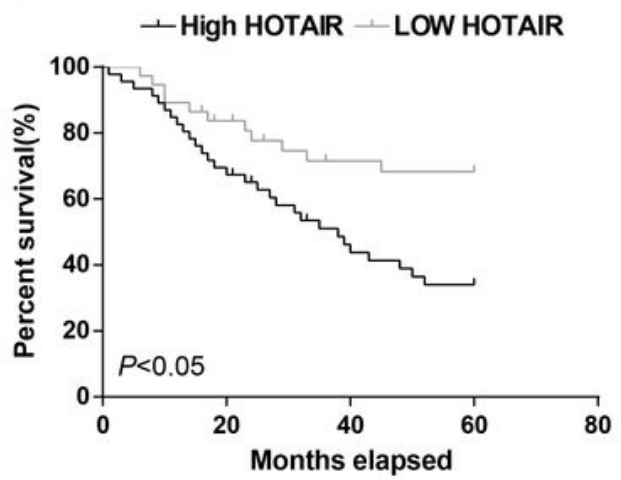

B

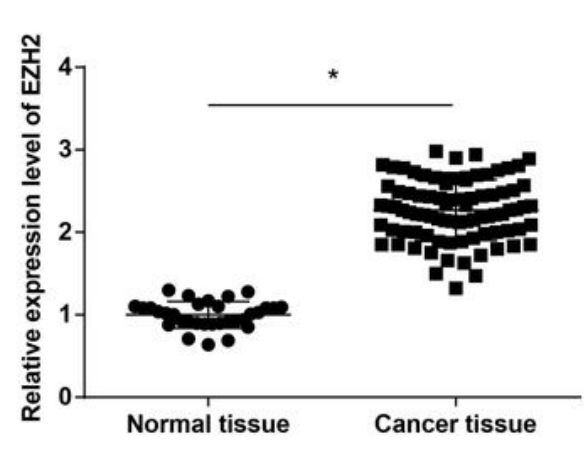

$\mathbf{E}$
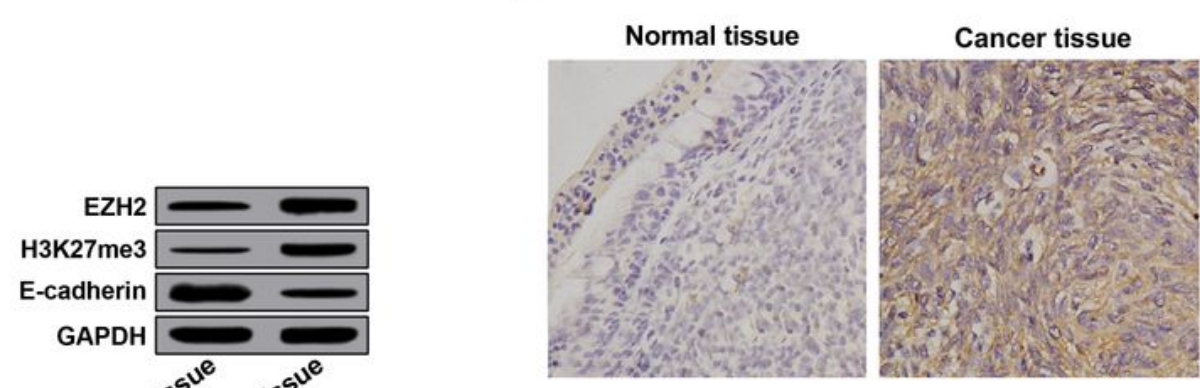

C

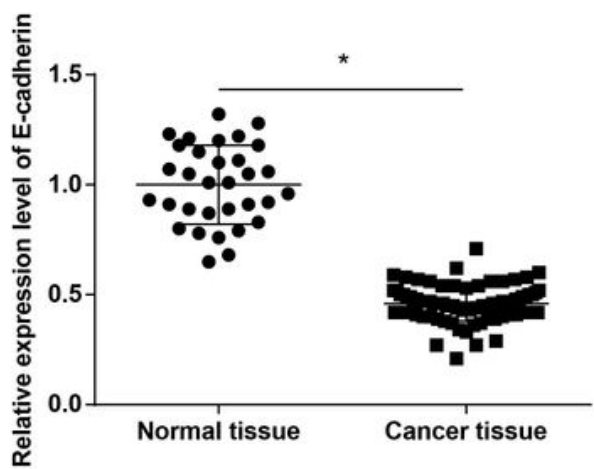

G
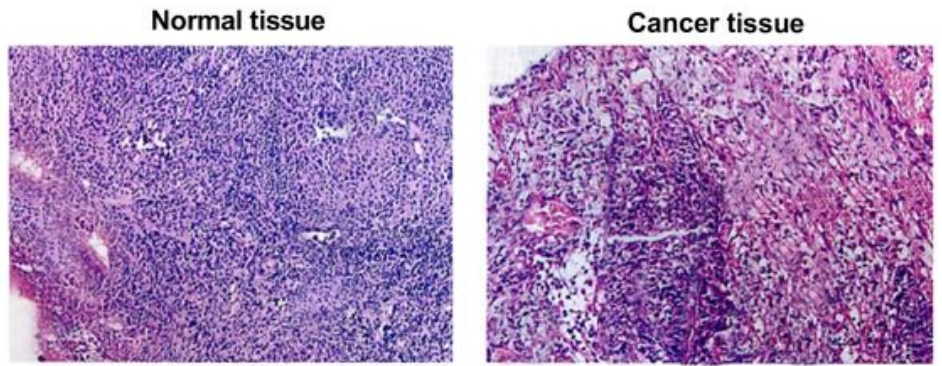

I

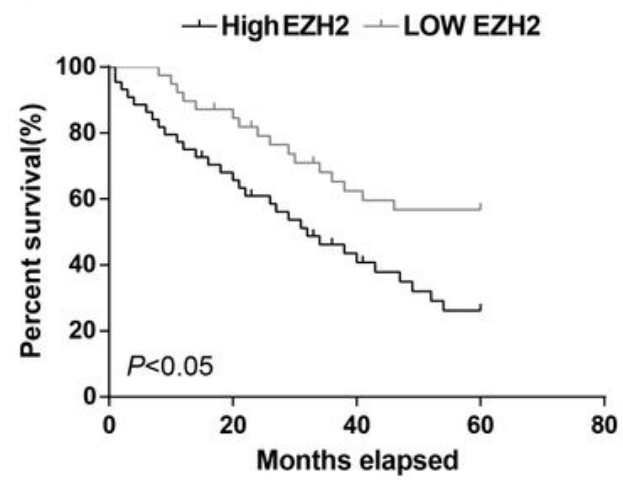




\section{Figure 1}

LncRNA HOTAIR, EZH2 and H3K27me3 are highly expressed and E-cadherin is poorly expressed in NPC patients. A. HOTAIR expression in NPC; B. EZH2 expression in NPC; C. E-cadherin expression in NPC; D. $\mathrm{EZH} 2, \mathrm{H} 3 \mathrm{~K} 27 \mathrm{me} 3$ and E-cadherin protein expression in NPC; E. Immunohistochemical staining detection of H3K27me3 expression in NPC; F. E-cadherin expression in NPC detected by immunohistochemistry; G. Histopathological changes in NPC observed by HE staining; H. HOTAIR expression on prognosis of patients with NPC; I. EZH2 on the prognosis of patients with NPC; the data in the figure were all measurement data, using the mean \pm standard deviation form, ${ }^{*} \mathrm{P}<0.05$ compared with the normal tissue group; Figure H, Figure I adopted Kaplan-Meier analysis for the survival and prognosis in patients with NPC. 
A

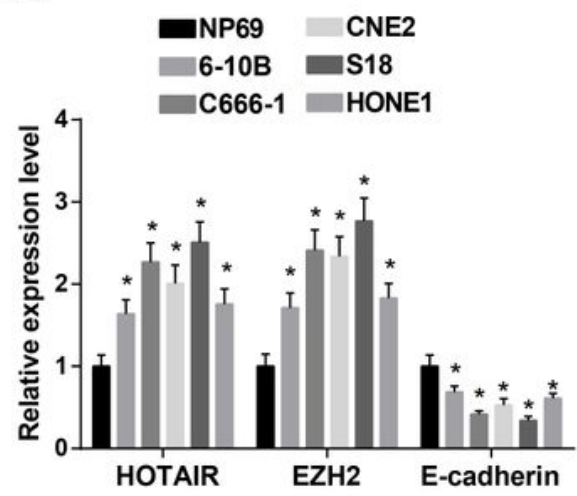

C

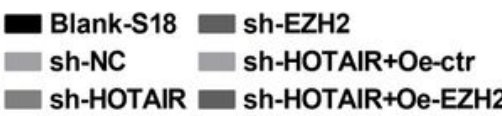

sh-ctr

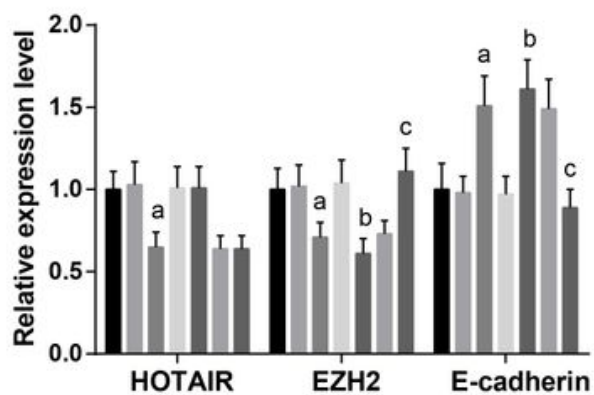

$\mathbf{E}$
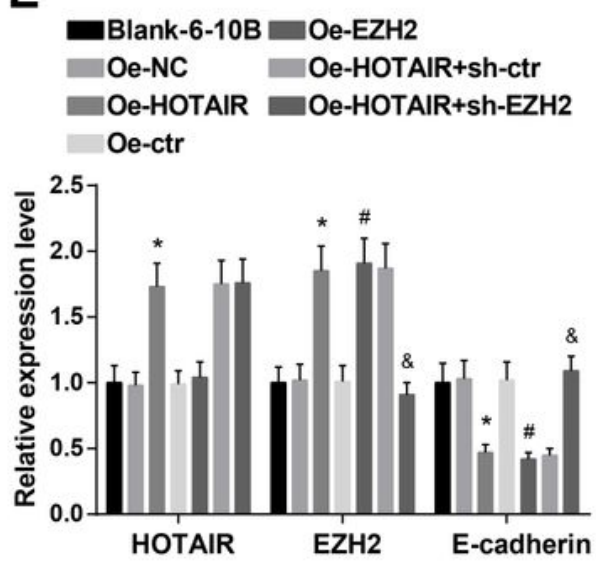

B

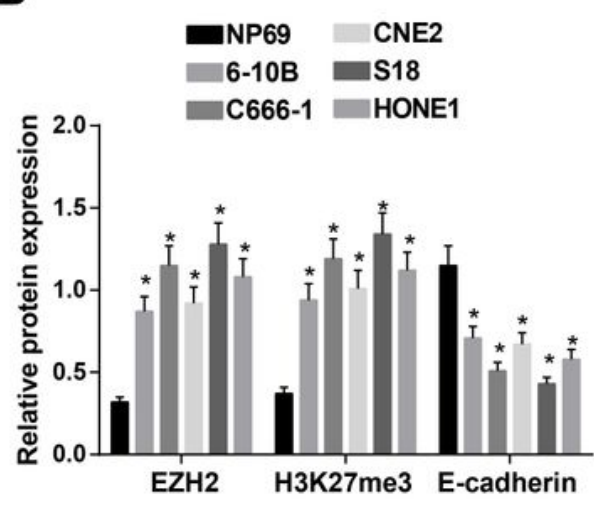

D
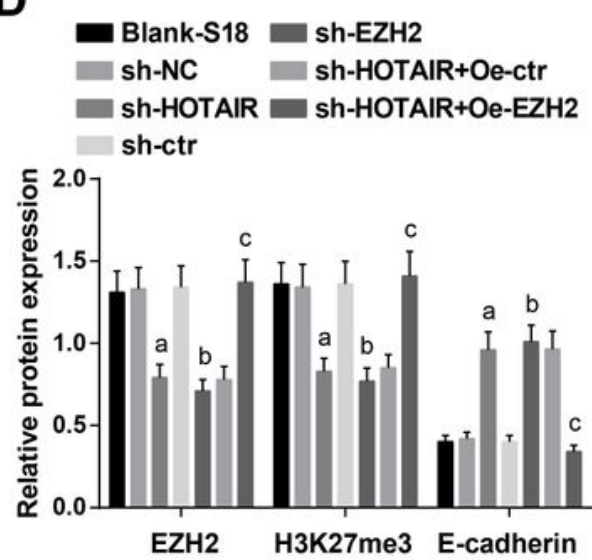

$\mathbf{F}$
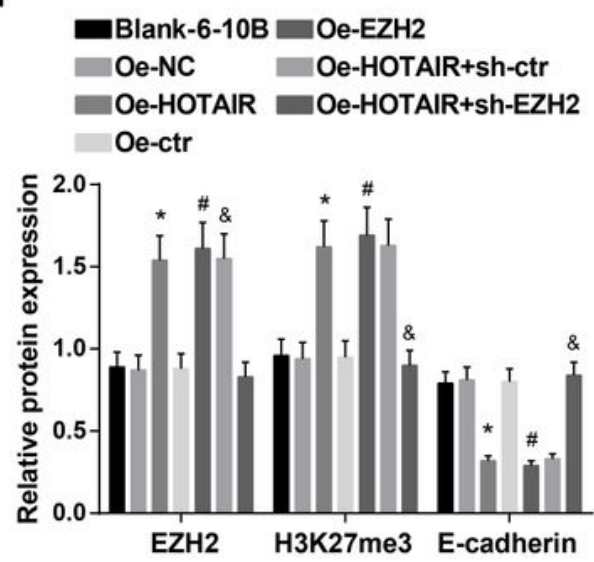
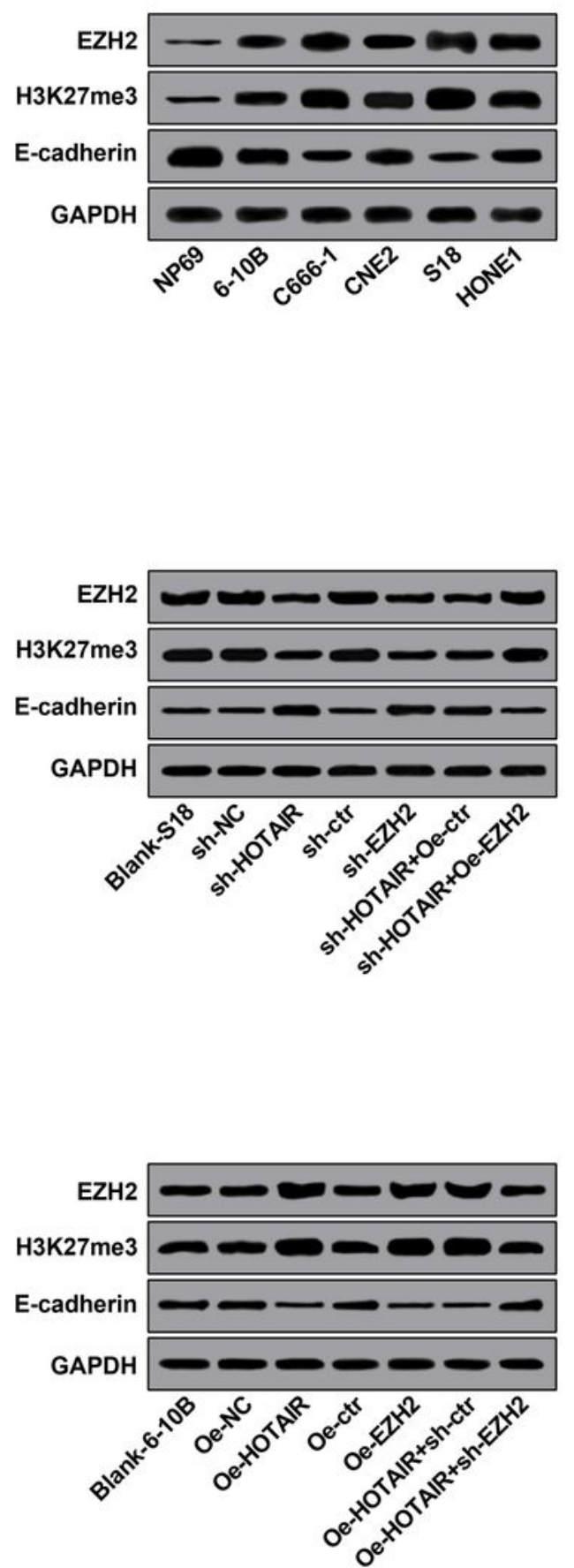

Figure 2

LncRNA HOTAIR, EZH2 and H3K27me3 are highly expressed and E-cadherin is poorly expressed in NPC cells. A. HOTAIR, EZH2, and E-cadherin expression in each cell line; B. EZH2, H3K27me3, and E-cadherin protein expressions in each cell line; C. HOTAIR, EZH2, and E-cadherin expression in S18 cells; D. EZH2, H3K27me3 and E-cadherin protein expression in each group of S18 cells; E. HOTAIR, EZH2 and E-cadherin expression in 6-10B cells of each group; $\mathrm{F}$. EZH2, H3K27me3 and E-cadherin protein expression in 6-10B 
cells of each group; the data in the figure were all measurement data, using the mean \pm standard deviation form, * $\mathrm{P}<0.05$ compared with NP69 cells.
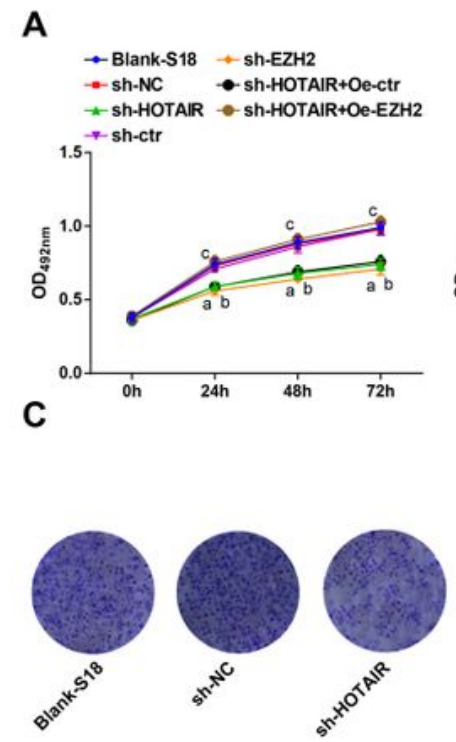

E
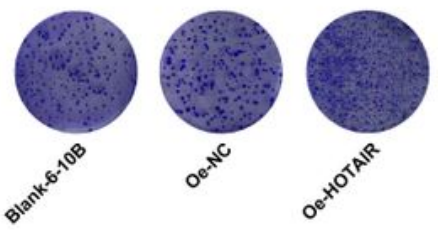

G

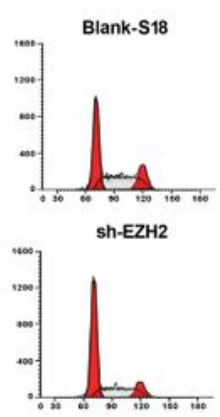

I
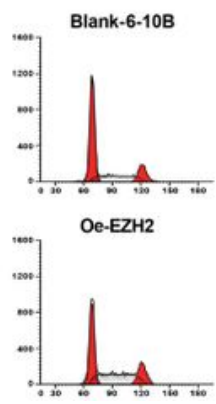
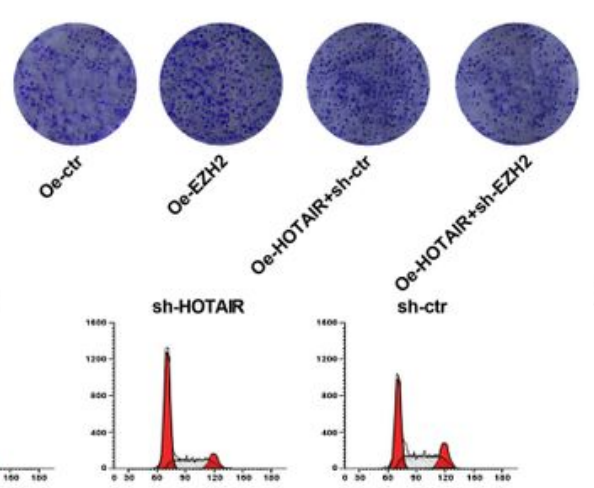

Sh-HOTAIR+Oe-EZH2
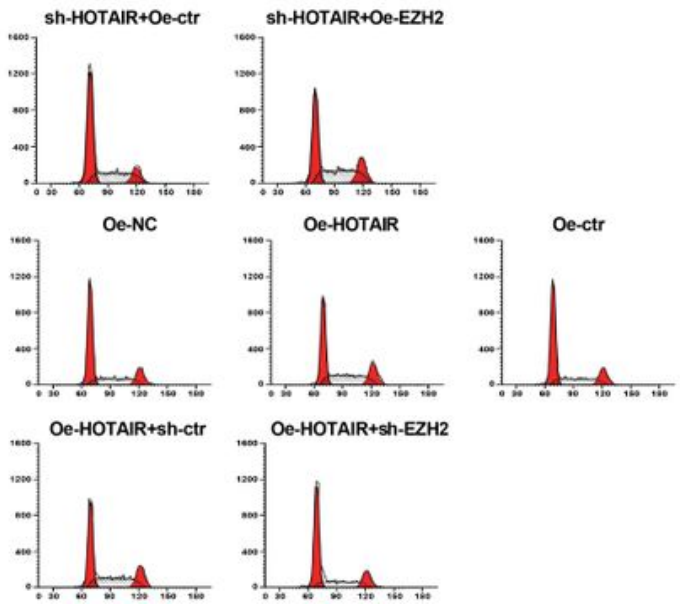

D

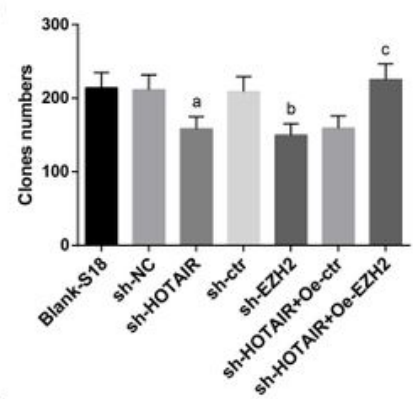

$\mathbf{F}$

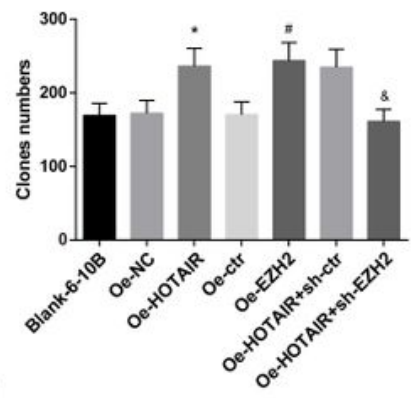

H
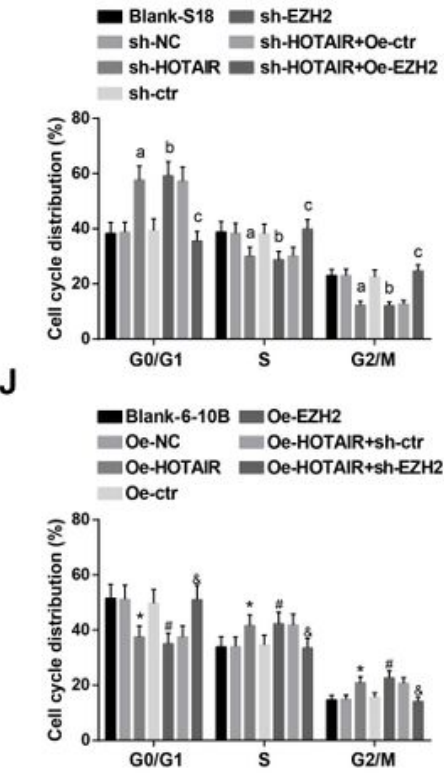

Figure 3

Down-regulation of HOTAIR or down-regulation of EZH2 suppresses cell viability, colony formation ability and cell cycle progression in NPC cells. A. Proliferation of S18 cells in each group detected by MTT assay; B. Proliferation of 6-10B cells in each group detected by MTT assay; C. Changes of colony forming ability 
of S18 cells in each group detected by colony formation assay; D. Number of colony formation of S18 cells in each group; E. Changes in colony formation ability of 6-10B cells in each group detected by colony formation assay; F. Number of colony formation of 6-10B cells in each group; G. Cell cycle changes of $\mathrm{S} 18$ cells in each group detected by flow cytometry; $\mathrm{H}$. Statistical data of cell cycle changes in each group of S18 cells; I. Cell cycle changes of 6-10B in each group detected by flow cytometry; J. Statistical chart of cell cycle changes of $6-10 \mathrm{~B}$ cells in each group; data in the figure were all measurement data, using mean \pm standard a deviation form; a $\mathrm{P}<0.05$ compared to the sh-NC group; $\mathrm{b} P$ $<0.05$ compared to the sh-Ctr group; $\mathrm{C}<0.05$ compared with the sh-HOTAIR + Oe-Ctr group; * $\mathrm{P}<0.05$ compared with the Oe-NC group; \# $\mathrm{P}<0.05$ compared with the Oe-Ctr group; \& $\mathrm{P}<0.05$ compared with the Oe-HOTAIR + sh-Ctr group. 
A

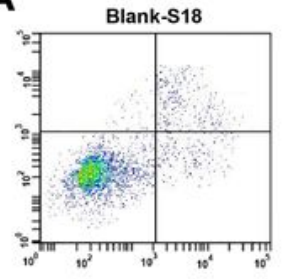

sh-EZH2

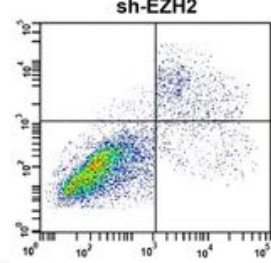

C
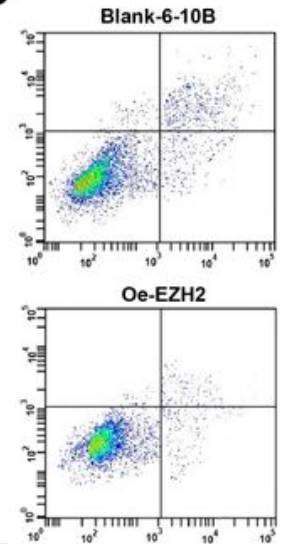

E
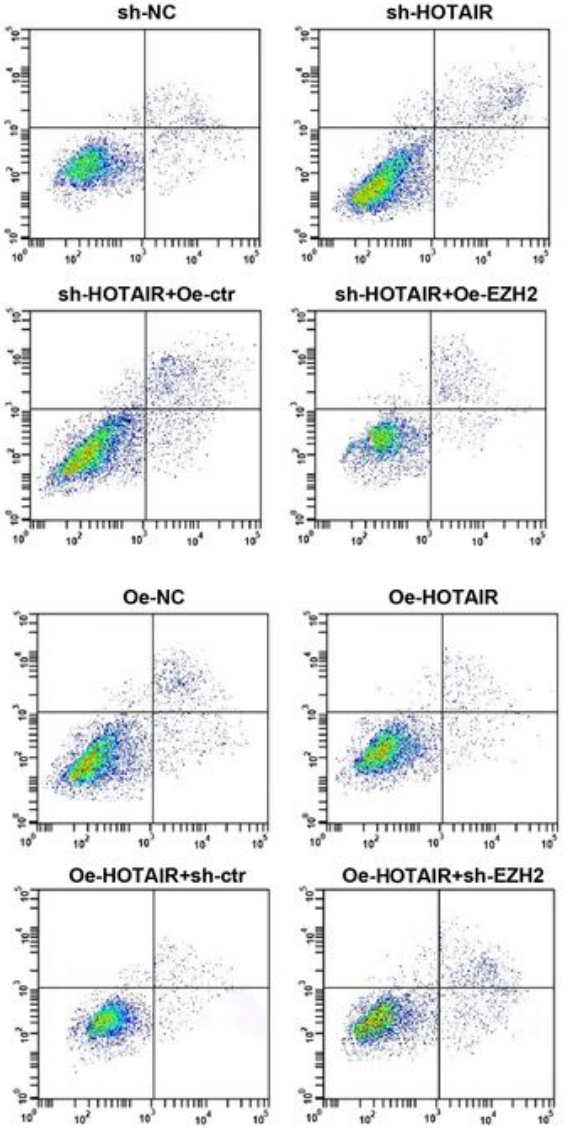

B
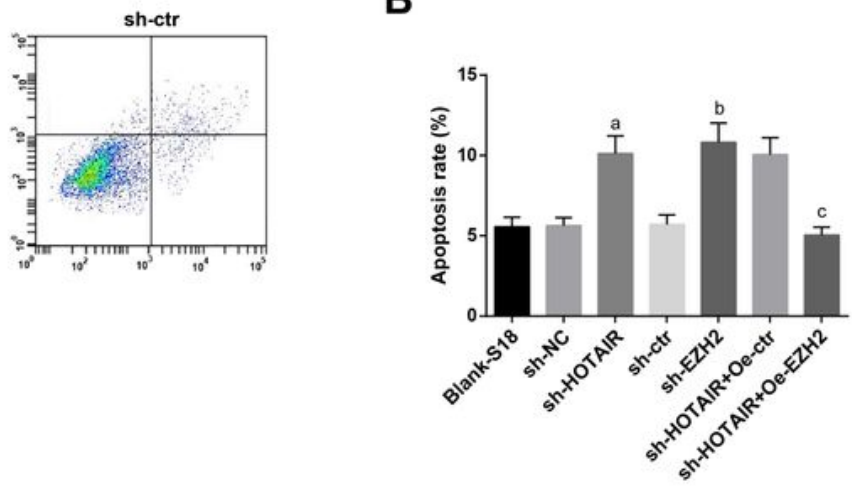

D

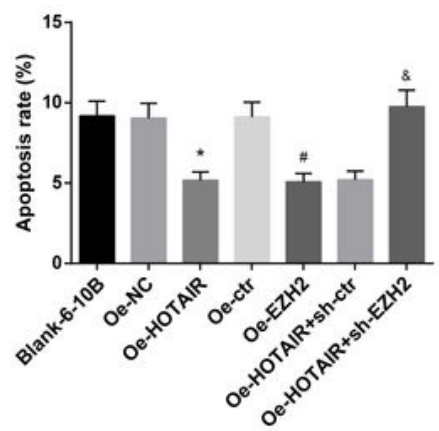

F

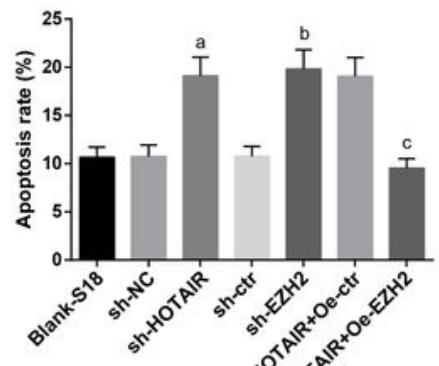

H

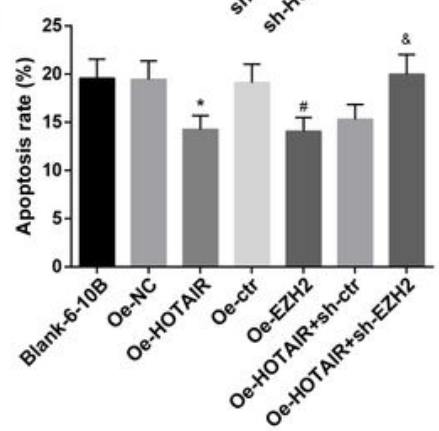

\section{Figure 4}

Down-regulation of HOTAIR or down-regulation of EZH2 promotes apoptosis in NPC cells. A. Changes of apoptosis rate of S18 cells in each group detected by flow cytometry; B. Changes of apoptosis rate of S18 cells in each group; C. Changes of apoptosis rate of 6-10B cells in each group detected by flow cytometry; D. Changes of apoptosis rate of 6-10B cells in each group; E. Changes of apoptosis rate of each group of S18 cells detected by Hoechst33342 fluorescent staining; F. Quantification results of Figure 
E; G. Change of apoptosis rate of 6-10B cells detected by Hoechst33342 fluorescent staining; $\mathrm{H}$.

Quantification results of Figure G; data in the figure were all measurement data, using mean \pm standard a deviation form; a P < 0.05 compared with the sh-NC group; b $\mathrm{P}<0.05$ compared with the sh-Ctr group; $\mathrm{C}$ $<0.05$ compared with the sh-HOTAIR + Oe-Ctr group; * $\mathrm{P}<0.05$ compared with Oe-NC group; \# $\mathrm{P}<0.05$ compared with Oe-Ctr group; \& P $<0.05$ with Oe-HOTAIR + sh-Ctr group.

A

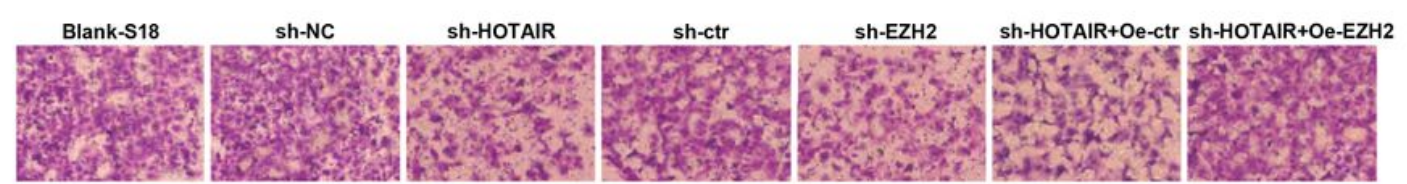

C

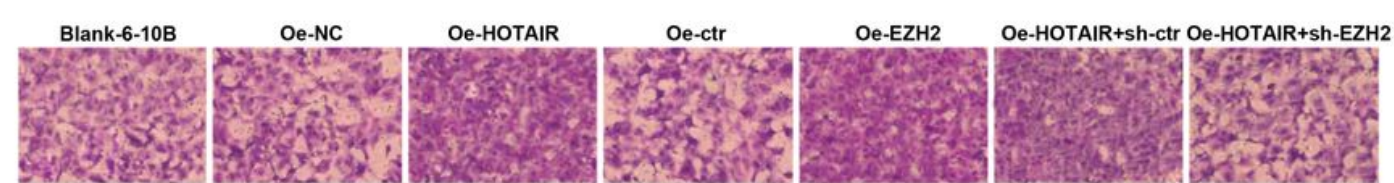

$\mathbf{E}$

B
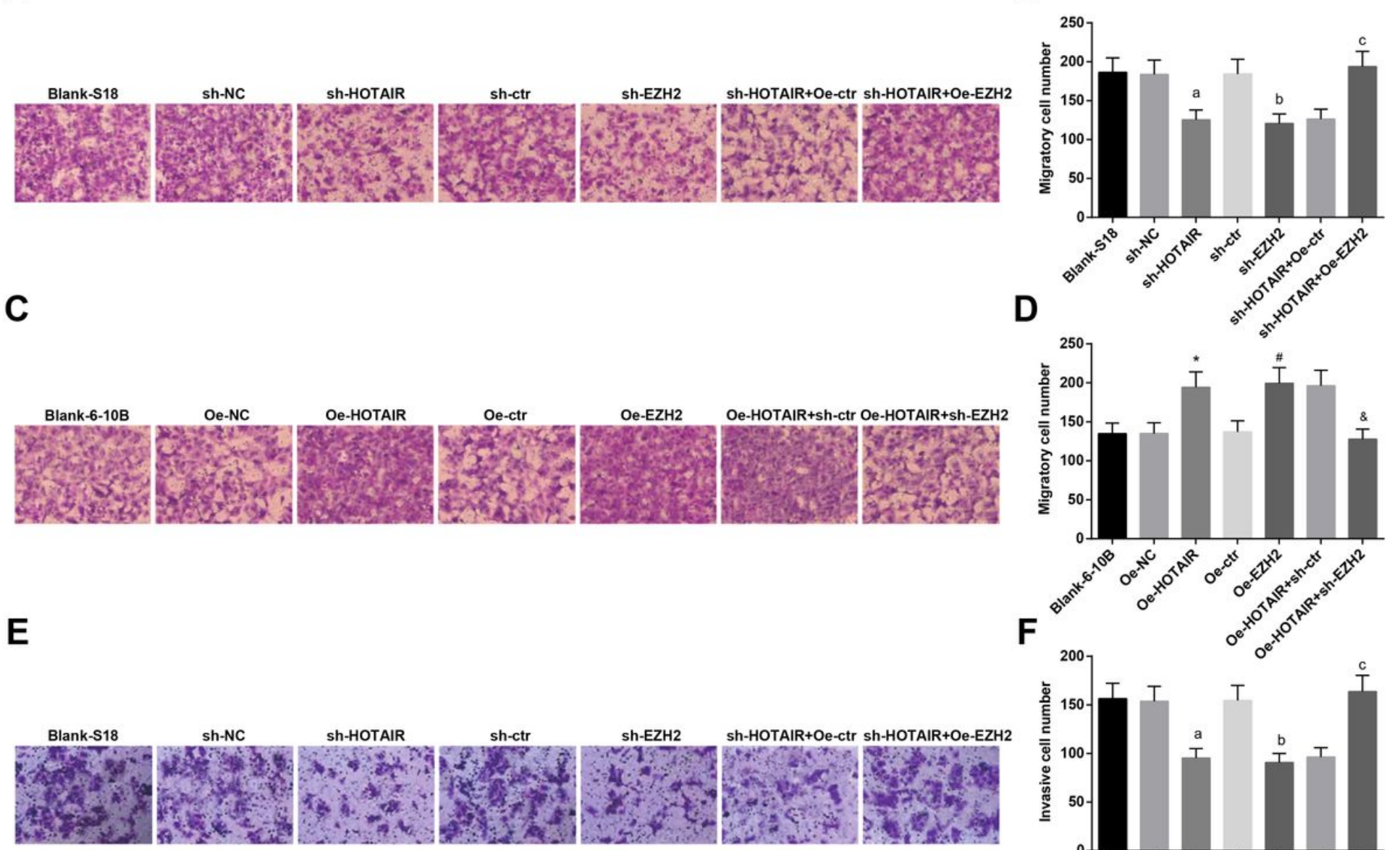

G

\section{H}
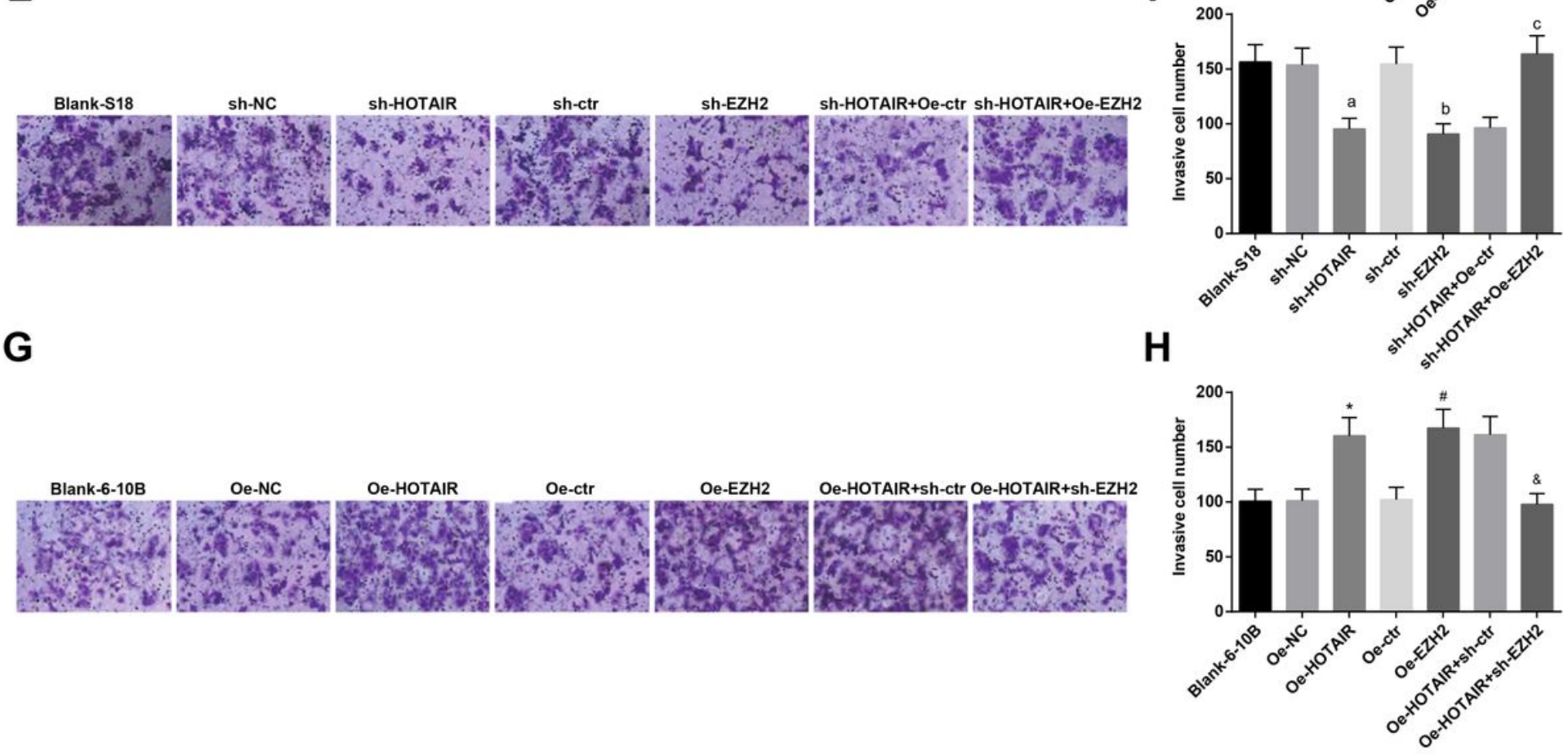

\section{Figure 5}

Down-regulation of HOTAIR or down-regulation of EZH2 inhibits cell migration and invasion of NPC cells. A. Migration ability of S18 cells in each group detected by Transwell assay; B. Quantification results of 
Figure A; C. Migration ability of 6-10B cells in each group detected by Transwell assay; D. Quantification results of Figure $\mathrm{C}$; E. Changes of invasion ability of S18 cells detected by Transwell assay; F.

Quantification results of Figure E; G: Changes of invasion ability of S18 cells detected by Transwell assay; $\mathrm{H}$. Quantification results of Figure $\mathrm{G}$; the data in the figure were all measured data, using mean \pm standard deviation form; a $\mathrm{P}<0.05$ compared with sh-NC group; $\mathrm{b} \mathrm{P}<0.05$ compared with sh-Ctr group; $\mathrm{c} P<0.05$ compared with sh-HOTAIR + Oe-Ctr group; * $\mathrm{P}<0.05$ compared with Oe-NC group; \# $\mathrm{P}<0.05$ compared with Oe-Ctr group; \& $\mathrm{P}<0.05$ compared with Oe-HOTAIR + sh- Ctr group.

A

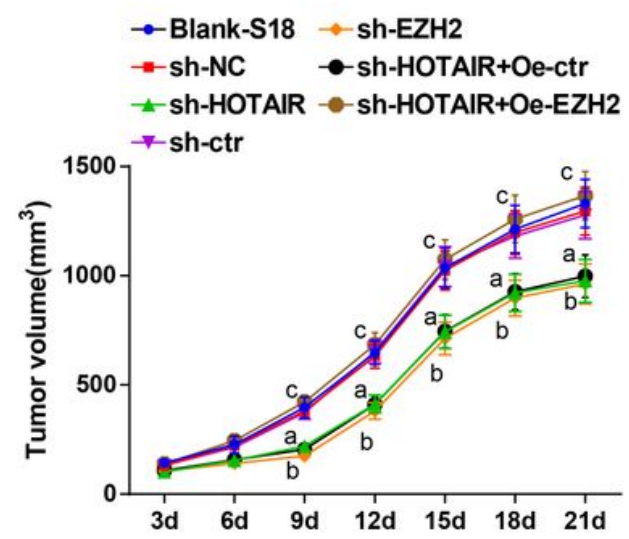

C
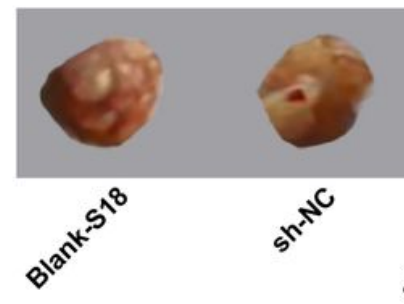

E
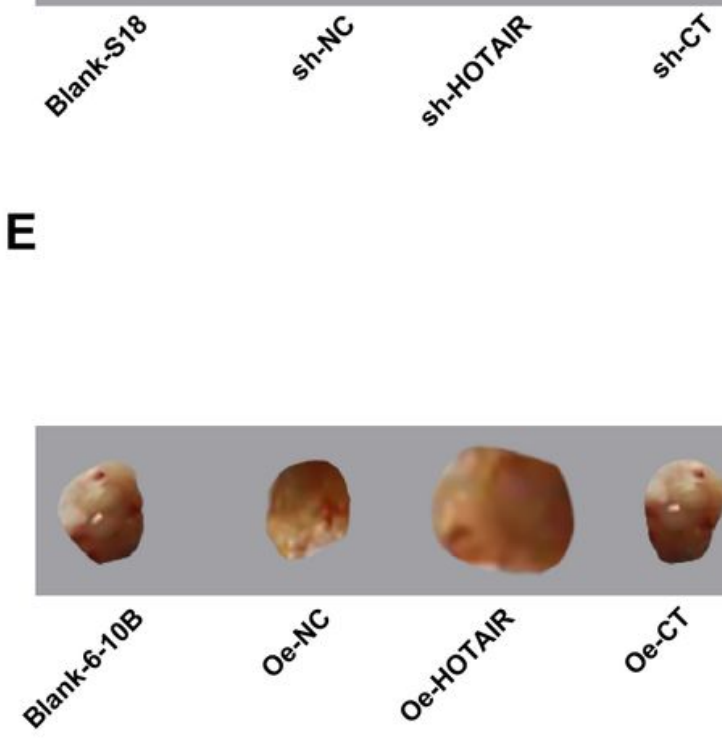

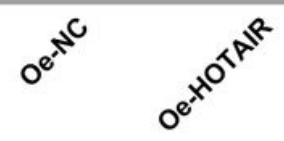

B

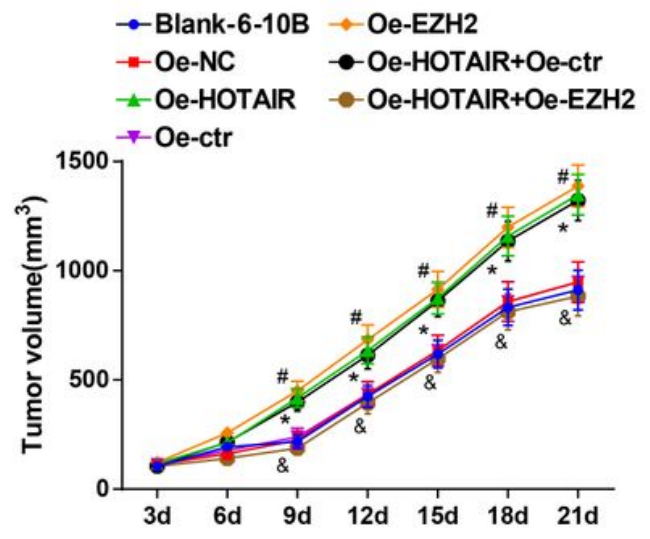

D

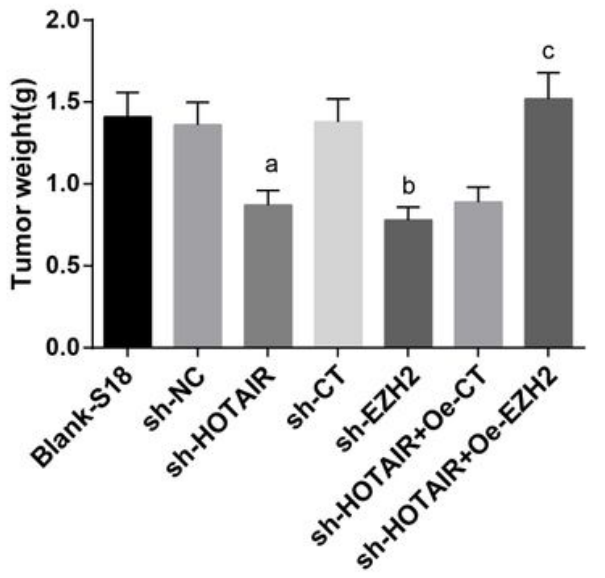

F

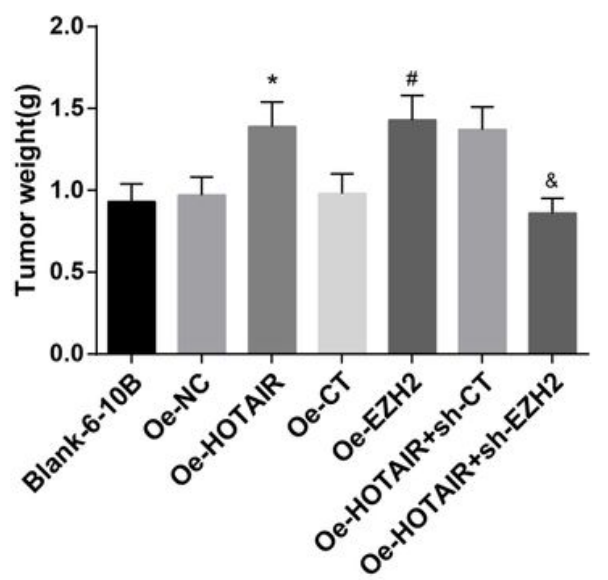

Figure 6 
Down-regulation of HOTAIR or down-regulation of EZH2 inhibits tumor growth and tumor volume in nude mice with NPC. A. Tumor volume in nude mice after S18 cell tumor tumorigenesis; $\mathrm{B}$. Tumor volume in nude mice after $6-10 \mathrm{~B}$ cell tumorigenesis; $\mathrm{C}$. Tumor observation of the nude mice in group on the 21 st day since S18 cell tumorigenesis; D. Tumor weight changes in each group on the 21 st day since S18 cell tumorigenesis; E. Tumor observation of the nude mice in group on the 21 st day since 6-10B cell tumorigenesis; F. Tumor weight changes in each group on the 21st day since 6-10B tumor tumorigenesis; the data in the figure were all measurement data, using the mean \pm standard deviation form; a $P<0.05$ compared with sh-NC group; b $\mathrm{P}<0.05$ compared with sh-Ctr group; $\mathrm{c} \mathrm{P}<0.05$ compared with sh -HOTAIR + Oe-Ctr group; * $\mathrm{P}<0.05$ compared with Oe-NC group; \# $\mathrm{P}<0.05$ compared with Oe-Ctr group; \& $\mathrm{P}<0.05$ compared with Oe-HOTAIR + sh-Ctr group.
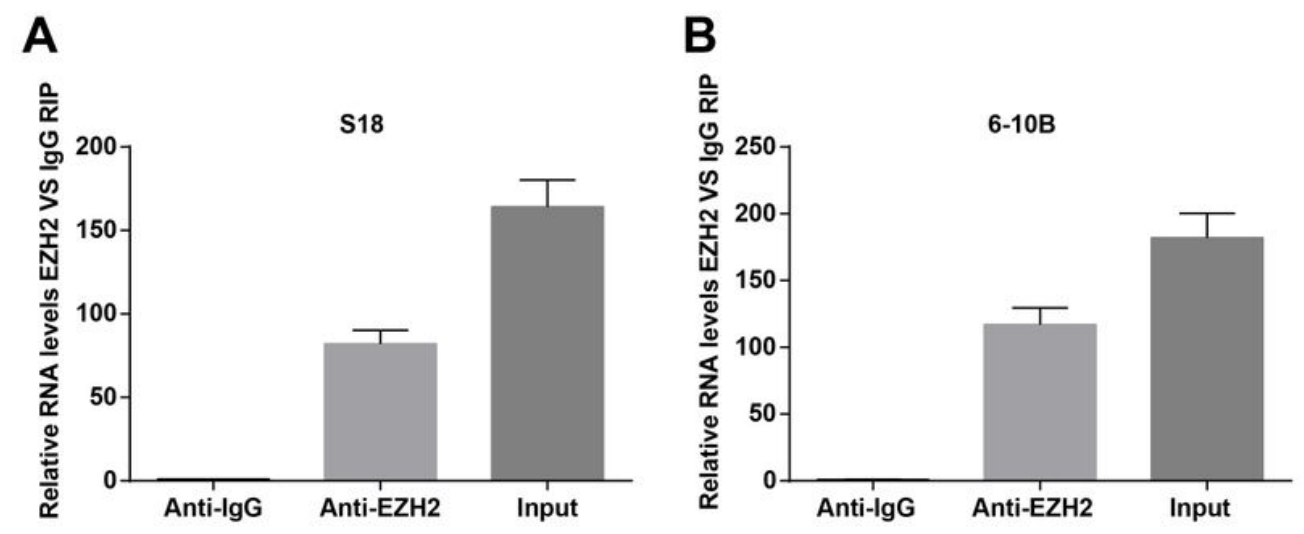

C
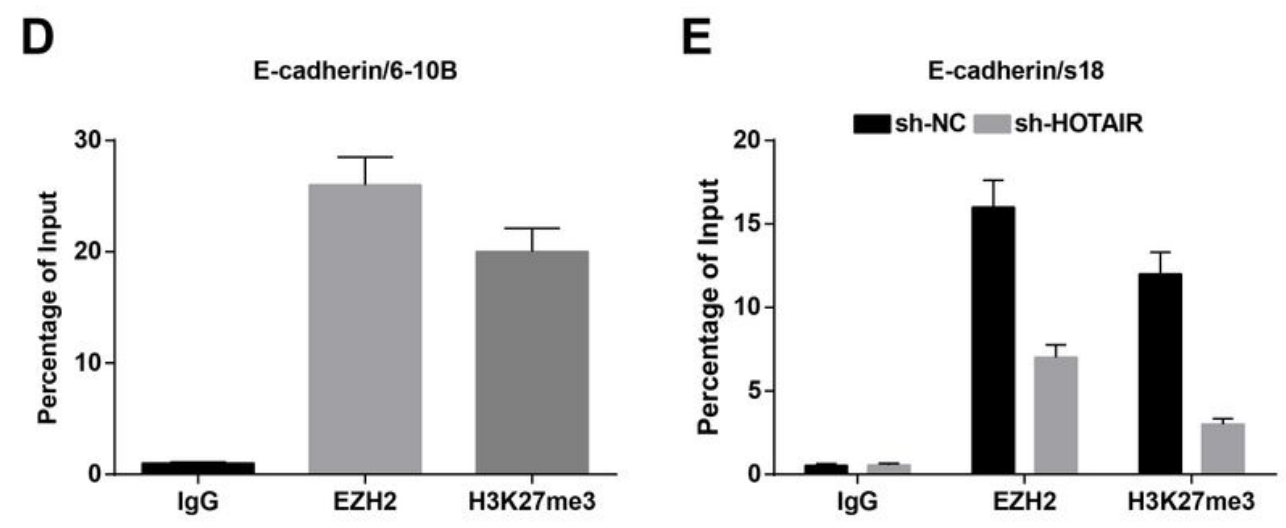

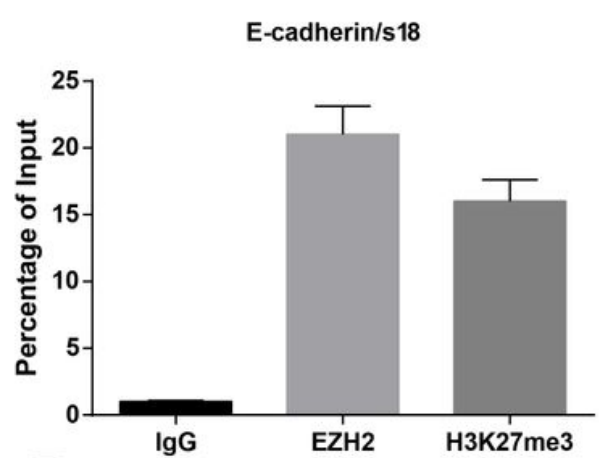

$\mathbf{F}$

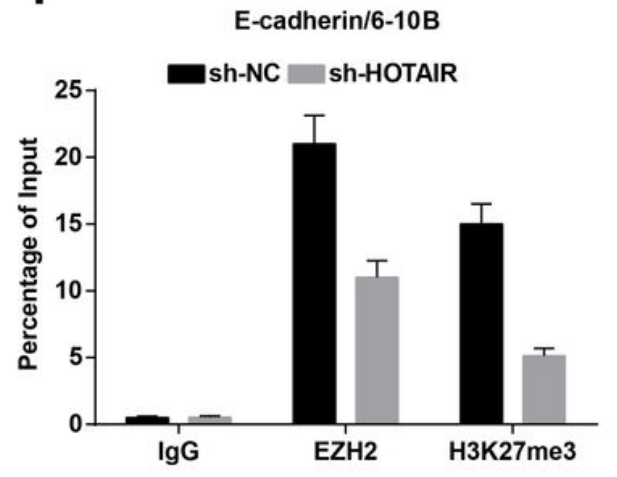

\section{Figure 7}

HOTAIR recruits histone methylase $\mathrm{EZH} 2$ to mediate trimethylation of $\mathrm{H} 3 \mathrm{~K} 27$ and to regulate $\mathrm{E}$-cadherin expression. A. RNA levels in EZH2, IgG or input co-precipitation of S18 cells detected by RT-qPCR; B. RNA levels in EZH2, IgG or input co-precipitaion of 6-10B cells detected by RT-qPCR; C. EZH2 and H3K27me3 binding abundance in E-cadherin promoter region in S18 cell line detected by ChIP-RT-qPCR; D: EZH2 and H3K27me3 binding abundance in E-cadherin promoter region in 6-10B cell line detected by ChIP-RT-qPCR; E. EZH2 and H3K27me3 binding abundance in E-cadherin promoter region in sh-HOTAIR-transfected S18 cell line detected by ChIP-RT-qPCR; F. EZH2 and H3K27me3 binding abundance in E-cadherin promoter region in sh-HOTAIR-transfected 6-10B cell line detected by ChIP-RT-qPCR; the data in the figure were all measurement data, using the mean \pm standard deviation form. 